\title{
Development of the Competence
} Measure of Individual Teacher-Student Relationships (COMMIT): Insight Into the Attitudes, Knowledge, and Self-Efficacy of Pre-service Teachers

\author{
Liedewij F. N. Borremans* and Jantine L. Spilt \\ School Psychology and Development in Context, KU Leuven, Leuven, Belgium
}

The importance of dyadic teacher-student relationships for both teachers and students is widely acknowledged. However, only limited research has explored how competent teachers feel in building these relationships. The current study aimed, first, to deepen

\section{OPEN ACCESS}

Edited by:

Claudio Longobardi,

University of Turin, Italy

Reviewed by:

Jeremy R. Sullivan,

University of Texas at San Antonio,

United States

Ariel Mariah Lindorff

University of Oxford, United Kingdom

${ }^{*}$ Correspondence:

Liedewij F. N. Borremans liedewij.borremans@kuleuven.be

Specialty section:

This article was submitted to Educational Psychology,

a section of the journal

Frontiers in Education

Received: 08 December 2021 Accepted: 07 February 2022 Published: 02 March 2022

Citation:

Borremans LFN and Spilt JL

(2022) Development of the Competence Measure of Individual

Teacher-Student Relationships (COMMIT): Insight Into the Attitudes, Knowledge, and Self-Efficacy

of Pre-service Teachers.

Front. Educ. 7:831468.

doi: 10.3389/feduc.2022.831468 the knowledge on relational competence by targeting teachers' competence in building dyadic teacher-student relationships specifically. To this end, the Competence Measure of Individual Teacher-student relationships (COMMIT) was developed. This questionnaire is explicitly based on theories used in research on affective teacher-student relationships and addresses multiple aspects of competence (attitudes, knowledge, and selfefficacy). Second, as teacher education programs have been repeatedly criticized for not sufficiently targeting relational competencies, the current study focused on pre-service teachers' perceived competence and aimed to explore differences in this competence across pre-service teachers in subsequent years of their teacher training. Criterion validity of the newly developed COMMIT was examined in a sample of preservice teachers in pre-primary and primary teacher education programs $(N=535)$. Six subscales were created, addressing pre-service teachers' attitude toward teacherstudent relationships (1 scale), their knowledge of teacher-student relationships and coping (2 scales), and their self-efficacy beliefs with regard to building closeness, coping with conflict, and reflective functioning (3 scales). Results showed that pre-service teachers had a rather positive attitude toward teacher-student relationships, and felt quite knowledgeable and self-efficacious, yet not in all aspects of dyadic relationshipbuilding. Results further revealed that pre-service teachers in the final year of teacher training felt more competent, yet, again, not for all aspects of dyadic relationshipbuilding. Notably, differences between pre-service teachers in subsequent years of teacher education were less pronounced in primary compared to pre- primary teacher education programs. Suggestions for future research and implications for initial teacher training are discussed.

Keywords: teacher-student relationship, teacher perceived competence, measure development, teacher education, dyadic teacher-student relationships, teacher attitudes, teacher self-efficacy 


\section{INTRODUCTION}

The importance of the affective qualities of dyadic teacherstudent relationships, both for child development and teacher well-being, has repeatedly been demonstrated (e.g., McGrath and Van Bergen, 2015; Corbin et al., 2019). Students who have a close relationship with their teacher for instance hold more positive attitudes toward school, achieve better in class, and are more likely to develop positive peer relations (Roorda et al., 2017, 2020; Ansari et al., 2020a), while students who have a conflictual relationship with their teacher are at risk for negative outcomes and the amplification of initial internalizing and externalizing problems (Roorda et al., 2014; Ansari et al., 2020a; Nguyen et al., 2020; Roorda and Koomen, 2021). Likewise, close teacher-student relationships contribute to teachers' self-efficacy, sense of personal accomplishment, job satisfaction, and professional motivation (Hagenauer et al., 2015; Zee et al., 2017; Corbin et al., 2019; Evans et al., 2019; Aboagye et al., 2020), whereas conflictual relationships are an important source of teacher stress and are predictive of burnout symptoms such as emotional exhaustion (Milatz et al., 2015; Corbin et al., 2019; Ansari et al., 2020b). In sum, both teachers and students profit from close relationships, while both suffer from conflictual relationships. Although the importance of affective teacher-student relationships is widely acknowledged, only limited research has focused on how competent teachers feel in building these relationships and how this competence can be influenced by, for example, teacher education. This study aimed to fill this gap and focused on teachers' perceived competence in dyadic relationship-building, specifically targeting pre-service teachers in (pre-) primary education programs.

\section{Affective Teacher-Student Relationships}

Within research on affective teacher-student relationships, attachment theory has become the dominant framework (Pianta, 1999; Sabol and Pianta, 2012; Verschueren and Koomen, 2012). The teacher-student relationship is conceptualized based on three dimensions: closeness, conflict, and dependency (Pianta, 2001). Closeness reflects the openness and warmth within the relationship, while conflict refers to resistance and disharmony in teacher-student interactions. Dependency, in turn, reflects (excessive) dependent behavior of the student toward the teacher (Verschueren and Koomen, 2012). The attachment framework states that in a positive, effective relationship, characterized by closeness and the absence of conflict and dependency, the teacher functions as a "secure base" and "safe haven" for students, allowing them to explore the world and supporting their further social, emotional and academic development (Pianta, 1999; Verschueren and Koomen, 2012). Attachment-based interventions emphasize the importance of teachers' reflective functioning, that is their ability to reflect upon their own and their students' emotions and cognitions (Slade, 2007; Spilt et al., 2012; Bosman et al., 2021). Moreover, the teacher's sensitivity, reflected in for instance their ability to take the students' perspective as well as to respond appropriately to each student's needs, is considered vital in building a warm, positive relationship (Pianta, 1999;
Koomen and Lont, 2004; Sabol and Pianta, 2012; Verschueren and Koomen, 2012).

Together with attachment theory, research often builds on the self-determination theory (Deci et al., 1991; Ryan and Deci, 2000). Self-determination theory states that every human has three fundamental, psychological needs: the need for autonomy, competence, and relatedness. Fulfillment of these needs is a requirement for motivation, engagement, and growth (Deci et al., 1991; Ryan and Deci, 2000). In a school context, this means that all three needs have to be fulfilled in order for students to truly engage and learn (Deci et al., 1991; Ryan and Deci, 2000; Opdenakker, 2014). Teachers are important actors who can support students in fulfilling these needs. In this light, the teacher-student relationship has been identified as an important lever to fulfill students' need for relatedness (Deci et al., 1991; Ryan and Deci, 2000; Opdenakker, 2014). Moreover, positive relationships with students can also fulfill the teachers' own need for relatedness (Klassen et al., 2012).

In addition to these two psychological approaches, educational scientists have studied the teacher-student relationship using the model of interpersonal teacher behavior. This model builds upon the communicative systems approach to model interactions between teachers and students (Wubbels et al., 2006, 2012a,b). Teacher behavior in the classroom is described along two dimensions, Dominance (also called "Influence," dominance vs. submission) and Affiliation (also called "Proximity," opposition vs. cooperation). By combining these two dimensions, the pattern of teacher behavior can be summarized in one of eight interpersonal styles (e.g., Leadership, Understanding, Strict; Wubbels et al., 2006, 2012a). Interactions between two parties can be either symmetrical or complementary. Within teacherstudent relationships, interactions are often symmetrical with regard to affiliation [i.e., cooperative or friendly behavior from the teacher elicits cooperative or friendly behavior from the student(s)], yet complementary with regard to dominance (i.e., dominant behavior from the teacher elicits submissive behavior from the student(s); Wubbels et al., 2006). Although the model of interpersonal theory behavior is most frequently used in research focused on classroom-level relationships, it has also been applied to the dyadic teacher-student relationship (Thijs et al., 2011; Roorda et al., 2012). On both the dyadic and classroom level, the teacher's interpersonal behavior was found to be related to cognitive and affective student outcomes (Wubbels et al., 2007, 2012b; Thijs et al., 2011; Roorda et al., 2012; Zijlstra et al., 2013).

As mentioned above, teachers interact with the class as whole, as well as with individual students. Although classroom-level and dyadic teacher-student relationships are related (Buyse et al., 2008; Moen et al., 2019; Walker and Graham, 2019), the impact of dyadic teacher-student relationships on student development can be distinguished from the impact of relationships at the classroom level (Buyse et al., 2009; Rucinski et al., 2018; Nguyen et al., 2020). A low-quality dyadic teacher-student relationship can subvert the benefits of high-quality classroom environments (Crosnoe et al., 2010; Nguyen et al., 2020) and classroom-level emotional support cannot compensate for lowquality dyadic relationships (Rucinski et al., 2018). These results 
highlight the importance of teachers' competence to build positive relationships with each of their students.

\section{Teachers' Relationship-Building Competence}

Although investing time and effort in building positive teacher-student relationships benefits both parties, researchers have suggested that teacher education programs might not sufficiently prepare teachers for building positive teacher-student relationships (Jo, 2014; Korpershoek et al., 2016; Rucinski et al., 2018; Aspelin and Jonsson, 2019). Teacher education programs have been criticized for focusing too strongly on (subject) knowledge and teaching skills rather than addressing didactical, pedagogical and relational competencies equally. If attention is given to pedagogical competencies, the focus is mainly on classroom management (Jensen et al., 2015; Aspelin and Jonsson, 2019). While reports from teachers and pre-service teachers revealed that they consider interactions and relationships with students the most difficult aspect of teaching (Jensen et al., 2015), only limited research has explored how competent (preservice) teachers feel in building teacher-student relationships with individual students and how teacher education impacts this perceived competence.

An important effort toward the inclusion of relational competencies in teacher training has been initiated, both in policy and research, in Denmark and Sweden (Jensen et al., 2015; Aspelin and Jonsson, 2019). In various, in-depth qualitative studies, researchers have investigated how (pre-service) teachers themselves conceptualize "relational competence," how relational competencies are visible in teachers' practice, and how teacher education can strengthen teachers' relational competencies (Jensen et al., 2015; Aspelin and Jonsson, 2019; Aspelin et al., 2020, 2021). This line of research conceptualizes relational competence as "being able to meet students and parents with openness and respect, to show empathy and to be able to take responsibility for one's own part of the relationship as an educator" (Jensen et al., 2015, p. 206). This approach does thus not solely focus on affective teacher-student relationships, nor does it determine specific skills or attitudes needed to build relationships with individual students. The current study aims to deepen the knowledge on relational competence by focusing on pre-service teachers' competence in building dyadic teacherstudent relationships.

Several quantitative measures have been developed to assess the quality of teacher-student relationships or interactions, both from the perspective of the student and the perspective of the teacher [for an overview of self-report measures, see Roza et al. (2021)]. However, to our knowledge, only two quantitative measures have been developed which target teachers' perceived relational competence ${ }^{1}$. First, in line with the multidimensional Scandinavian framework, the Teacher's

\footnotetext{
${ }^{1}$ Although frequently used measures of teacher self-efficacy (e.g., TschannenMoran and Woolfolk Hoy, 2001; Zee et al., 2016) refer to several aspects of the teacher-student relationship (e.g., "How much can you do to calm a student who is disruptive or noisy?" as part of classroom management, or "How well can you provide a safe and secure environment for this student?" as part of emotional support), relationship-building skills of teachers are not explicitly addressed and
}

Relational Competence Scale (TRCS; Vidmar and Kerman, 2016) addresses teachers' authenticity, responsibility, and respect for individuality in teacher-student relationships. Notably, only two scales, responsibility and individuality, were retained: the expected, theory-based three-factor structure including authenticity was not supported (Vidmar and Kerman, 2016). Relational competence as measured with the TRCS, combining responsibility and individuality, was shown to positively predict teachers' job satisfaction (Perše et al., 2020). Second, the unidimensional Teacher Relational Self-Efficacy Scale (TRSES; Robinson, 2020) assesses teachers' feelings of relational self-efficacy: "teachers' beliefs about their capability to successfully form, maintain, and repair relationships with students" (Robinson, 2020, p. 2). The dissertation research of Robinson (2020) suggested that relational self-efficacy is predictive of teacher-student relationship quality, over and above self-efficacy in other aspects of teaching.

However, neither of these existing measures seem to be specific enough to address dyadic relationship-building competence. First, development of these measures was guided by socialemotional competence research and teacher self-efficacy research, respectively, rather than theoretical perspectives on dyadic teacher-student relationships such as the attachment framework, self-determination theory and the theory of interpersonal teacher behavior (Vidmar and Kerman, 2016; Robinson, 2020). As a result, the value of these measures notwithstanding, the existing measures do not distinguish between classroom-level relationships and dyadic teacher-student relationships. However, it is possible that teachers feel generally competent in building relationships with their students (e.g., how much can you do to get your students to trust you?), yet they feel less competent in their interactions with one or two specific students (e.g., do you know for each individual student in your class how to calm or console them when they are angry or upset or do you know this for most, but not all students?). As this study focuses on dyadic relationships, the measure used should be tailored to these one-on-one relationships. As discussed, prominent theories in research on dyadic teacher-student relationships are attachment theory, self-determination theory as well as the theory of interpersonal teacher behavior. We argue that when targeting teachers' perceived dyadic relationship-building competence, at least the most prominent aspects of these theories (e.g., for attachment theory: how the teacher can function as a secure base) should be included.

Second, the mentioned measures target only one aspect of teachers' perceived competence, namely teachers' self-efficacy beliefs. However, both theoretical models of competence (Baumert and Kunter, 2013; Blömeke and Kaiser, 2017) and empirical research emphasize that different aspects of teachers' competence - that is teachers' affect-motivation (attitudes or beliefs) (theoretical) knowledge, and self-efficacy beliefs separately contribute to their teaching practice (Kunter et al., 2013; Spruce and Bol, 2014; Charalambous, 2015; Depaepe and König, 2018; Horzum and Izci, 2018; Yu, 2018). Notably,

we do not consider these measures specific enough to assess the concept of relational competence. 
studies investigating whether teachers' self-efficacy beliefs, most often in the domain of emotional support, are associated with dyadic teacher-student relationship quality have yielded mixed results (Zee and Koomen, 2016, 2017; Hajovsky et al., 2020). It might thus be necessary to include teachers' attitudes and knowledge as well to fully capture associations between teachers' perceived competence and actual performance (i.e., relationship quality).

Finally, the discussed measures of relational competence focus primarily on the students' relational and supportive needs: what can, or should, the teacher do to support the student? However, the teacher is also part of the relationship and what the teacher needs to be able to support the student should not be overlooked. It is not always evident to build close teacher-student relationships with each and every student in your class, and how teachers cope with negative emotions and conflicts in interactions with students is crucial to preserve and maintain teacher sensitivity (Koenen et al., 2019a; Ansari et al., 2020b). For example, if a teacher wants to calm down or console the student following a conflict, they need to be able to cope with their own emotions. Only then can they restore the relationship. In building teacher-child relationships, teachers are the ones responsible for trying to establish, maintain and, if needed, restore the relationship. Negative teacher emotions and cognitions, such as helplessness or not feeling in control, can discourage the teacher from searching for new strategies to connect with a student, might cause teachers to withdraw from a student, and can undermine their sensitivity toward that student (Chang and Davis, 2009; Spilt and Koomen, 2009; Koenen et al., 2019a). The ability to cope with these negative emotions and cognitions, however, can strengthen teachers' resilience and is crucial in preventing teachers from becoming discouraged in the face of challenges, such as repeated conflict with students (Hastings and Brown, 2002; Beltman et al., 2011).

Teachers need to regulate their emotions and (maladaptive) cognitions both in the moment and in the long run (Hastings and Brown, 2002; Beltman et al., 2011; Pillen et al., 2013; Wang et al., 2019; Zaretsky and Katz, 2019; de Ruiter et al., 2021). The use of maladaptive coping strategies (e.g., hiding or faking emotions; cognitive avoidance) in interactions with students decreases occupational well-being, puts teachers at risk for burnout, and can subvert the development of positive teacher-student relationships (Hastings and Brown, 2002; Beltman et al., 2011; Wang et al., 2019; de Ruiter et al., 2021). In contrast, adaptive coping (e.g., reflecting upon your own emotions; keeping calm; problem solving) enhances teachers' resilience in dealing with conflict with students and allows teachers to build positive relationships (Whitaker et al., 2015; McGrath and Van Bergen, 2019; Zaretsky and Katz, 2019; de Ruiter et al., 2021). We therefore argue that adaptive coping with negative emotions and conflict is a core aspect of teachers' dyadic relationship-building competence. When targeting pre-service teachers' dyadic relationshipbuilding competence it might thus be especially valuable to assess how teachers react to difficult interactions with students [e.g., giving up or getting frustrated when dealing with disruptive behavior (maladaptive) or searching for a new solution (adaptive)].

\section{The Present Study}

Seeking a more profound understanding of teachers' perceived competence in dyadic relationship-building and to explore differences between pre-service teachers in different phases of their teacher education in this competence, we developed a measure explicitly based on theories used in research on dyadic teacher-student relationships (attachment theory, selfdetermination theory, theory of interpersonal teacher behavior), which addresses multiple aspects of competence (attitudes, knowledge and self-efficacy) and includes both student-oriented competencies (e.g., taking the students' perspective) and teacheroriented competencies [e.g., (mal)adaptive coping].

In a sample of pre-service teachers in pre-primary and primary education programs we first investigated construct validity using exploratory and confirmatory factor analysis. Next, criterion validity was examined. We aimed to examine whether perceived dyadic relationship-building competence was positively associated with pre-service teachers' general teacher self-efficacy and feelings of competence, emotional intelligence, affect-motivation, and well-being. First, with regard to general teacher self-efficacy and competence, we expected to find a relatively strong, positive association between dyadic relationship-building competence and the more general, broader concept of relational self-efficacy as these concepts are closely related. Furthermore, we expected pre-service teachers who feel competent as a teacher and student in general, to feel more competent in dyadic relationship-building as well. We thus expected a moderate to strong, positive association with general teacher self-efficacy and a smaller, positive association with academic self-concept. Second, as emotional intelligence is a requirement for both student- and teacher-oriented dyadic relationship-building competencies, we expected small to moderate associations between dyadic relationship-building competence and emotional intelligence. Emotional intelligence is considered to be a multidimensional construct, including both appraisal and regulation of emotions, with both a focus on one-self and on the other (Pekaar et al., 2018). We more specifically expected to find associations between studentoriented dyadic relationship-building competencies and otherfocused emotional appraisal and regulation as well as between teacher-oriented dyadic relationship-building competencies and self-focused emotional appraisal and regulation. Third, with regard to affect-motivation we expected small to moderate associations with job motivations (including motivations related to a desire for contact with students and motivations related to a desire to contribute to the future of students), and with studentoriented beliefs (vs. subject matter-oriented beliefs). Finally, as poor well-being and in particular depressive symptoms might negatively influence competence perceptions (Gable and Shean, 2000), we included a measure of depression. We expected small negative associations between dyadic relationship-building competence and depression.

In addition, differences between pre-service teachers in subsequent years of the teacher education program 
were explored. As teacher education programs have been criticized for not sufficiently targeting relationship-building competencies, we expected only small differences between pre-service teachers in different cohorts. Relatedly, we explored differences between the pre-primary and primary teacher education programs. In line with the predominance of early childhood, as compared to middle or late childhood, in research on teacher-student relationships (Verschueren, 2015), preservice teachers in the pre-primary teacher education program might feel more competent compared to teachers in the primary education program.

\section{MATERIALS AND METHODS}

\section{Sample}

A sample of 535 pre-service teachers (88.7\% female) from three university colleges participated in the study. Pre-service teachers both from pre-primary (69.0\%) and primary $(30.8 \%)$ programs, as well as from all three years of the programs (1st year cohort: $46.4 \%$; 2 nd year cohort: $23.4 \%$; 3 rd year cohort: $30.1 \%$ ) participated. Mean age of pre-service teachers was 21.9 years $(S D=4.4$; range $=19$ to 51$)$. Sample characteristics for each university college separately are summarized in Table $\mathbf{1}$.

\section{Procedure and Recruitment \\ Recruitment of Teacher Training Programs}

In Flanders, initial teacher education programs typically entail 3 years and consist of both theoretical courses and internships. All 11 university colleges who offer pre-primary and/or primary teacher training at a professional bachelor level in Flanders were invited to participate. An e-mail was sent to department heads of teacher education programs including a short summary of the study and an invitation to ask any questions and to explore

TABLE 1 | Sample characteristics for each university college.

\begin{tabular}{|c|c|c|c|c|c|c|c|c|}
\hline $\begin{array}{l}\text { Sample } \\
\text { characteristic }\end{array}$ & \multicolumn{2}{|c|}{ College A } & \multicolumn{2}{|c|}{ College B } & \multicolumn{2}{|c|}{ College C } & \multicolumn{2}{|c|}{ Full sample } \\
\hline$N$ & \multicolumn{2}{|r|}{112} & \multicolumn{2}{|c|}{232} & \multicolumn{2}{|c|}{191} & \multicolumn{2}{|c|}{535} \\
\hline \multicolumn{9}{|l|}{ Age } \\
\hline Mean $(S D)$ & \multicolumn{2}{|c|}{$21.80(4.56)$} & \multicolumn{2}{|c|}{22.41 (5.55) } & \multicolumn{2}{|c|}{$21.40(2.09)$} & \multicolumn{2}{|c|}{$21.93(4.41)$} \\
\hline \multirow[t]{2}{*}{ Range } & \multicolumn{2}{|c|}{$19-47$} & \multicolumn{2}{|c|}{$19-51$} & \multicolumn{2}{|c|}{ 19-36 } & \multicolumn{2}{|c|}{$19-51$} \\
\hline & $n$ & $\%$ & $n$ & $\%$ & $n$ & $\%$ & $n$ & $\%$ \\
\hline \multicolumn{9}{|l|}{ Gender } \\
\hline Female & 98 & 87.50 & 193 & 83.19 & 183 & 95.81 & 474 & 88.76 \\
\hline Male & 13 & 11.61 & 37 & 15.95 & 7 & 3.67 & 57 & 10.65 \\
\hline Not indicated & 1 & 0.89 & 2 & 0.86 & 1 & 0.01 & 4 & 0.75 \\
\hline \multicolumn{9}{|l|}{ Program } \\
\hline Pre-primary & 68 & 60.71 & 111 & 47.85 & 191 & 100 & 369 & 68.97 \\
\hline Primary & 44 & 39.29 & 121 & 52.16 & 0 & 0 & 165 & 30.84 \\
\hline \multicolumn{9}{|l|}{ Year } \\
\hline 1st year & 44 & 39.29 & 143 & 61.64 & 61 & 31.94 & 248 & 46.36 \\
\hline 2nd year & 42 & 37.50 & 22 & 9.48 & 61 & 31.94 & 125 & 23.36 \\
\hline 3rd year & 25 & 22.32 & 67 & 28.88 & 69 & 36.13 & 161 & 30.09 \\
\hline
\end{tabular}

further collaboration. Three university colleges agreed, with three pre-primary and two primary teacher education programs participating in the study.

\section{Recruitment of Pre-service Teachers}

All pre-service teachers of the participating programs were invited to complete the questionnaire, there were no exclusion criteria. The online questionnaire was distributed during a(n online) class of a compulsory course. Pre-service teachers first received information about the study either in a short video summary or live from the researcher and were then invited to complete the questionnaire. Informed consent was obtained at the start of the online survey. If pre-service teachers indicated they did not wish to participate, the questionnaire was not shown. Pre-service teachers were able to quit the questionnaire at any time without consequences. Movie tickets were raffled among participants as an incentive.

\section{Procedure}

Ethical approval was granted prior to the start of the research by the authors' research institute. First, a smaller group of pre-service teachers $(N=156)$ was recruited to pilot the questionnaire. The researcher was present during the pilot data collection to answer questions and to record any feedback or remarks from the participating pre-service teachers (e.g., the phrasing of some questions was unclear; the questionnaire was perceived as too long). Second, adaptions were made to the questionnaire and additional pre-service teachers $(N=379)$ were recruited for the main study. In total, 576 pre-service teachers were invited to participate in the study. 41 questionnaires $(7.12 \%)$ were not started (i.e., no consent obtained) or showed indications of inattentive response [e.g., non-random answer patterns such as choosing the same option throughout the full questionnaire, including reverse scored items, Meade and Craig (2012)]. These questionnaires were excluded from the study, resulting in the final sample of 535 pre-service teachers.

\section{Questionnaire Development}

Teachers' perceived competence in dyadic relationship-building was assessed for three aspects of competence (Baumert and Kunter, 2013; Blömeke and Kaiser, 2017): affect-motivation (attitudes or beliefs), knowledge and self-efficacy. The items were constructed based on a literature review focused on the discussed theories (attachment theory, self-determination theory and theory of interpersonal teacher behavior) and on teacher-oriented competencies required for building relationships (understanding of emotions and coping). Further on, example items are provided for each part of the questionnaire ${ }^{2}$. Content of the items and format of the questionnaire were discussed with experts in the field of teacher-student relationships as well as teacher educators from our partner university colleges. Based on their feedback, items were adapted to both reflect the current state of the art of research on dyadic teacher-student relationships and to resonate well with pre-service teachers. Finally, based on explorative factor

\footnotetext{
${ }^{2}$ The original items are in Dutch, available upon request. The items presented in the methods and results section have not been translated to English using backtranslation procedures.
} 
analyses in a pilot study $(N=156), 8$ additional items were added to the questionnaire in order to strengthen preliminaryfound subscales.

The first part of the questionnaire addressed pre-service teachers' affect-motivation, particularly their attitudes, beliefs and motivation concerning teacher-student relationships, e.g., "A personal relationship with the teacher is important, but it is not crucial for the quality of education." Twenty items were rated on a five-point scale ranging from 1 (totally disagree) to 5 (totally agree). We expected one affect-motivation scale to emerge.

The second part of the questionnaire addressed pre-service teachers' knowledge of the discussed theories (attachment theory, self-determination theory, theory of interpersonal teacher behavior, understanding of emotional experiences and coping) and related constructs regarding dyadic relationship-building in 18 items, e.g., an item addressing knowledge based on the attachment framework "I understand how a teacher can provide a secure base for a child" or an item addressing knowledge of coping strategies "I understand which coping skills are efficient when I feel stressed in the classroom." Each item was constructed in this way, starting with "I understand...." The goal was not to test whether pre-service teachers' knowledge is correct, but rather to assess the level of mastery pre-service teachers think they have obtained. Pre-service teachers indicated to what extent they are familiar with the constructs on a scale ranging from 1 [I don't understand this (yet)] to 5 (I fully understand this, and I am able to explain it to my peers). A priori, we expected one set of items mainly targeting a theoretical understanding of teacher-student relationships (e.g., how a relationship with a student can be described in terms of control and affiliation) to form one scale, while we expected a second set of items mainly targeting a theoretical understanding of emotional experiences, relational-emotional coping and self-care (e.g., which emotions teachers often experience in interactions with students) to form a second scale. Additionally, four non-relationship content items, covering other domains of teaching, were added. These items described contents taken from the so called 'professional profile and start competencies' of teachers of the department of education (Aelterman et al., 2008), which are presumed to be amply included in and repeated throughout teacher training (e.g., powerful learning environment, difference between formative and summative evaluation). These items were used as filler items and therefore not included in our analyses.

The third part of the questionnaire addressed pre-service teachers' dyadic relationship-building self-efficacy. The structure of this part was inspired by the Perceived Competence Scale for Children (Harter, 1982). Thirty-two bipolar items gave two descriptions of teachers, e.g., "Some teachers can get through to every child in their classroom" and "Other teachers can get through to some, but not to all children in their classroom" (see Figure 1). Pre-service teachers were asked to indicate where they position themselves between those two statements, indicating to what extent either the right or left statement is true for them (1 through 6, very typical of me, sort of typical of me, not that typical of me, not that typical of me, sort of typical for me, very typical of me). A priori, we expected one set of items mainly targeting self-efficacy in building teacher-student relationships (student-oriented competencies, e.g., being aware of the interests, feelings, ideas, and goals of each student) to form one scale, while we expected a second set of items mainly targeting self-efficacy in relational-emotional coping and self-care (teacher-oriented competencies, e.g., keeping your emotions in check during conflicts with students) to form a second scale.

\section{Instruments for Validation ${ }^{3}$ Teacher Self-Efficacy and Competence}

First, the Teachers' Relational Self-Efficacy Scale (TRSES; Robinson, 2020) consists of eight items (e.g., "How confident are you that you can build positive relationships with all your students?", $\omega=0.86, \alpha=0.86$ ) targeting teachers' beliefs about their "capability to successfully form, maintain and repair relationships with students" (Robinson, 2020, p. 17). Items were rated on a five-point Likert scale ranging from 1 (Not at all confident) to 5 (Extremely confident). First evidence was found for the reliability and validity of the TRSES in a sample of middle and high school teachers in dissertation research (Robinson, 2020).

Second, to capture pre-service teachers' perceptions about themselves as a teacher, we included the widely used Teacher Self-Efficacy Scale (TSES; Tschannen-Moran and Woolfolk Hoy, 2001). The TSES comprises three subscales: efficacy in instructional strategies (6 items, e.g., "To what extent can you craft good questions for your students?”, $\omega=0.87, \alpha=87$ ), classroom management (5 items, e.g., "How much can you do to control disruptive behavior in the classroom?", $\omega=0.92$, $\alpha=0.92$ ) and student engagement (5 items, e.g., "How much can

\footnotetext{
${ }^{3}$ As recently has been argued to use Omega rather than Cronbach's alpha to evaluate scale reliability (e.g., Peters, 2014; Hayes and Coutts, 2020), yet Cronbach's alpha is still most often used, we included both indices in this manuscript.
}

$\begin{array}{llllll}\begin{array}{l}\text { Very typical } \\ \text { of me }\end{array} & \begin{array}{l}\text { Sort of } \\ \text { typical of me }\end{array} & \begin{array}{l}\text { Not that } \\ \text { typical of me }\end{array} & \begin{array}{l}\text { Not that } \\ \text { typical of me }\end{array} & \begin{array}{l}\text { Sort of } \\ \text { typical of me }\end{array} & \begin{array}{l}\text { Very typical } \\ \text { of me }\end{array}\end{array}$

Some teachers can get through to every child in their classroom

\author{
Other teachers can \\ get through to some, \\ but not to all \\ children in their \\ classroom
}


you do to foster student creativity?", $\omega=0.91, \alpha=0.90)$. Preservice teachers indicated their response on a nine-point Likert scale ranging from 1 (nothing) to 9 (a great deal). One student engagement item, focused on pupils' families, was removed as this is less relevant for pre-service teachers. All subscales were highly correlated with one another ( $r s$ from 0.66 to 0.74 ). Across grades and countries, the TSES has shown satisfactory reliability and construct validity, including in a Belgian sample of primary school teachers (Tschannen-Moran and Woolfolk Hoy, 2001; Klassen et al., 2009; De Smul et al., 2018).

Third, to capture pre-service teachers' perceptions about themselves as a student, we adapted the academic self-concept subscale of the Self-Concept Scale (Mertens, 1997) to apply to a context of higher education (10 items, e.g., "I am a smart student," "I am happy with my study results," $\omega=0.88, \alpha=0.87$ ). Preservice teachers indicated how they feel or think about themselves on a four-point scale ranging from 1 (not at all applicable) to 4 (very applicable). Evidence for the reliability and convergent validity of the academic subscale was found in a sample of 700 Belgian students (Mertens, 1997; Germeijs and De Boeck, 2002).

\section{Emotional Intelligence}

The Rotterdam Emotional Intelligence Scale (REIS; Pekaar et al., 2018) consists of 28 items and measures four aspects of emotional intelligence: self-focused emotion appraisal (7 items, e.g., "I understand why I feel the way I feel," $\omega=0.88, \alpha=0.87$ ), selffocused emotion regulation ( 7 items, e.g., "I can suppress my emotions easily," $\omega=0.81, \alpha=0.80$ ), other-focused emotion appraisal (7 items, e.g. "I know which feelings others experience," $\omega=0.88, \alpha=0.88)$ and other-focused emotion regulation (7 items, e.g., "I know what to do to improve people's mood," $\omega=0.87, \alpha=0.87$ ). Pre-service teachers indicated the extent to which they agree with each item on a five-point Likert scale ranging from 1 (totally disagree) to 5 (totally agree). All four subscales were moderately, yet significantly, correlated with one another ( $r$ s from 0.20 to 0.50 ). The REIS showed good reliability as well as convergent and discriminant validity in diverse Dutch samples, including pre-service teachers (Pekaar et al., 2018).

\section{Teacher Affect-Motivation}

We used the Teacher Beliefs Questionnaire developed by de Vries et al. (2013) to distinguish between pre-service teachers' subjectmatter orientated beliefs (7 items, e.g., "In my teaching, it is important that I pass on my subject matter to the students," $\omega=0.84, \alpha=0.84$ ) and student orientated beliefs (5 items, e.g., "In my teaching, it is important to relate to the students" own knowledge and experiences," $\omega=0.81, \alpha=0.81$ ). Both subscales were positively correlated $(r=0.59)$. The Teacher Beliefs Questionnaire showed high reliability in a Dutch sample of secondary school teachers (de Vries et al., 2013).

A second questionnaire targeted the career motivations of pre-service teachers, why they want to become a teacher and chose teacher training (De Cooman et al., 2007). Pre-service teachers indicated to what extent they agree that a certain motive convinced them to start their study to become a teacher on a five-point scale ranging from 1 (totally disagree) to 5 (totally agree). The expected subscales social role (4 items), transfer of knowledge (4 items), student contact (4 items) and variety and challenge ( 3 items) were not reliable $(\alpha$ 's $\leq 0.66)$ in our pilot study. Instead, based on exploratory factor analysis we created two scales. To shorten the questionnaire following the pilot study, only these two scales were included in the main study as well: student contact (5 items, e.g., "I am motivated to be a teacher because of the contacts with students," $\omega=0.80, \alpha=0.80)$ and social role of the teacher ( 4 items, e.g., "I am motivated to be a teacher because I want to participate in the future of young people," $\omega=0.71, \alpha=0.71$ ). Both subscales were highly correlated $(r=0.67)$.

\section{Well-Being}

Pre-service teachers completed the short version (10 items, $\omega=0.88, \alpha=0.87)$ of the Center for Epidemiological Studies Depression Scale (CES-D; Radloff, 1977). To shorten the questionnaire in order to reduce the workload for participants, a planned missingness, within-block design was administered in the main study (Rhemtulla and Hancock, 2016). Three items were completed by all participants. The remaining items were attributed to either form A, B, C, or D based on the pilot study data. Items that correlated strongly in the pilot study were attributed to different forms, whereas items that correlated less strongly were attributed to the same form (Rhemtulla and Hancock, 2016). Participants were randomly assigned to complete two of these forms.

\section{RESULTS}

\section{Factorial Validity Exploratory Factor Analysis}

In accordance with guidelines on scale development (Flora and Flake, 2017), we first performed exploratory factor analysis (EFA) before proceeding to confirmatory analysis (CFA). A random subsample $(N=156)$ was drawn from the main study sample (excluding the pilot study sample) for EFA. To account for the use of ordinal values and an asymmetrical distribution, EFA was based on the polychoric correlation matrix (Watkins, 2018). The number of factors was chosen based on parallel analysis, interpretation of the scree plot, and eigen values of the factors (Costello and Osborne, 2005; Montoya and Edwards, 2020). Items were retained if the factor loading was larger than $|0.40|$ and no cross loadings greater than $|0.32|$ were observed (Costello and Osborne, 2005; Watkins, 2018). The three questionnaire parts were analyzed separately. Factor loadings are reported in Tables 2-4. First, for affect-motivation a one-factor solution was found. This factor was comprised of 11 items and explained $21 \%$ of the variance with factor loadings ranging from $|0.41|$ to $|0.78|$. Second, for knowledge two factors were retained. Factor 1 included 10 items and explained 29\% of the variance with factor loadings from 0.56 to 0.86 . Factor 2 included 5 items and explained $18 \%$ of the variance with factor loadings from 0.45 to 1.08. Finally, for self-efficacy a three-factor solution was chosen. Factor 1 included 11 items and explained $12 \%$ of the variance with factor loadings from 0.41 to 0.59 . Factor 2 included 8 items and explained $12 \%$ of the variance with factor loadings from 0.49 to 
TABLE 2 | Results of exploratory factor analysis for affect-motivation: factor loadings.

\begin{tabular}{|c|c|}
\hline Item & Loading \\
\hline $\begin{array}{l}\text { Item 4: Personal relationships with students offer me personal } \\
\text { satisfaction }\end{array}$ & 0.78 \\
\hline $\begin{array}{l}\text { Item 15: As a teacher, I strive to have a personal relationship with } \\
\text { each student in the class }\end{array}$ & 0.74 \\
\hline Item 7 : I regret when a relationship with a student is rather impersonal & 0.63 \\
\hline $\begin{array}{l}\text { Item 2: Each student deserves a personal relationship with their } \\
\text { teacher }\end{array}$ & 0.60 \\
\hline $\begin{array}{l}\text { Item 10: Personal relationships with students are my number one } \\
\text { priority }\end{array}$ & 0.58 \\
\hline $\begin{array}{l}\text { Item 14: I want to be a teacher who understands every student in } \\
\text { their class through and through }\end{array}$ & 0.49 \\
\hline $\begin{array}{l}\text { Item 12: I am motivated to understand how personal relationships } \\
\text { with students can touch me personally }\end{array}$ & 0.47 \\
\hline $\begin{array}{l}\text { Item 9: Relationships with students can teach me something about } \\
\text { who I am }\end{array}$ & 0.46 \\
\hline $\begin{array}{l}\text { Item 3: A personal relationship with a student is important, but not } \\
\text { crucial for the quality of education }\end{array}$ & -0.55 \\
\hline $\begin{array}{l}\text { Item 5: Teachers cannot do much when they experience problems in } \\
\text { personal relationships with students }\end{array}$ & -0.43 \\
\hline $\begin{array}{l}\text { Item 18: Teachers have a rather small impact on a personal } \\
\text { relationship with a student }\end{array}$ & -0.41 \\
\hline $\begin{array}{l}\text { Item 16: Personal relationships with students make it easier to } \\
\text { maintain order in the classroom }\end{array}$ & 0.32 \\
\hline $\begin{array}{l}\text { Item 11: It is important to question my own behavior in a conflict with } \\
\text { a student }\end{array}$ & 0.29 \\
\hline $\begin{array}{l}\text { Item 8: It is impossible to build a personal relationship with each } \\
\text { student }\end{array}$ & -0.38 \\
\hline $\begin{array}{l}\text { Item 6: Other things in education are more important than building a } \\
\text { personal relationship with each student }\end{array}$ & -0.36 \\
\hline Item 1: Teacher stress is caused by difficult student behavior & -0.16 \\
\hline Item 19: Difficult student behavior hinders a personal relationship & -0.16 \\
\hline $\begin{array}{l}\text { Item 13: It is inevitable that you sometimes have a poor relationship } \\
\text { with a student }\end{array}$ & -0.10 \\
\hline $\begin{array}{l}\text { Item 17: The personal relationship with a student is strongly impacted } \\
\text { by the student's personality }\end{array}$ & -0.08 \\
\hline $\begin{array}{l}\text { Item 20: The personal relationship with a student is strongly impacted } \\
\text { by the student's family background }\end{array}$ & -0.04 \\
\hline
\end{tabular}

Factor loadings above 0.40 are in bold.

0.75 . Factor 3 included 6 items and explained $11 \%$ of the variance with factor loadings from 0.52 to 0.74 .

\section{Confirmatory Factor Analysis and Scale Reliability}

The exploratory factor solution was confirmed in the remaining sample ( $N=379$, combining pilot and main study sample) and compared to the a priori solution based on item content (for knowledge and self-efficacy) ${ }^{4}$. Factor loadings and a short description of the items are presented in Tables 5-8. Due to the ordinal nature of our data, models were fitted using diagonally weighted least squares (DWLS) estimation. It should be noted that using DWLS estimation tends to result in more extreme fit measures compared to other estimators (Xia and Yang, 2019) and conventional cut-off criteria (Hu and Bentler, 1999) should be

${ }^{4}$ Confirmatory factor analyses using only the remaining main study sample yielded similar results, with fit indices differing at most 0.01 .
TABLE 3 | Results of exploratory factor analysis for knowledge: factor loadings.

\begin{tabular}{|c|c|c|}
\hline Item & Factor 1 & Factor 2 \\
\hline $\begin{array}{l}\text { Item 4: Why a warm, personal relationship is important for } \\
\text { exploration and motivation of students }\end{array}$ & 0.86 & -0.26 \\
\hline $\begin{array}{l}\text { Item 17: How behavioral problems can be an expression of } \\
\text { emotional insecurity }\end{array}$ & 0.79 & -0.10 \\
\hline Item 9: Function of the teacher as a secure base & 0.78 & -0.13 \\
\hline $\begin{array}{l}\text { Item 12: How a relationship can be strengthened through } \\
\text { supporting the students' need for competence, belonging, } \\
\text { and autonomy }\end{array}$ & 0.74 & -0.11 \\
\hline Item 2: Emotional security & 0.70 & -0.08 \\
\hline $\begin{array}{l}\text { Item 15: How friendly teacher behavior elicits friendly } \\
\text { student behavior }\end{array}$ & 0.66 & 0.18 \\
\hline $\begin{array}{l}\text { Item 16: How authoritarian teacher behavior elicits defiant } \\
\text { student behavior }\end{array}$ & 0.62 & 0.13 \\
\hline $\begin{array}{l}\text { Item 20: Why a warm, personal relationship is important for } \\
\text { students' academic achievement }\end{array}$ & 0.59 & 0.14 \\
\hline Item 6: Resilience & 0.56 & 0.13 \\
\hline $\begin{array}{l}\text { Item 10: How a personal relationship with a student } \\
\text { influences me as a teacher }\end{array}$ & 0.56 & 0.22 \\
\hline $\begin{array}{l}\text { Item 22: How I can effectively cope with emotions and } \\
\text { stress I experience in the classroom }\end{array}$ & -0.31 & 1.08 \\
\hline $\begin{array}{l}\text { Item 13: Which coping skills are efficient when I feel } \\
\text { stressed }\end{array}$ & -0.29 & 0.92 \\
\hline $\begin{array}{l}\text { Item 14: How a relationship with a student can be } \\
\text { described in terms of control and affiliation }\end{array}$ & 0.12 & 0.62 \\
\hline Item 8: Emotional labor & 0.03 & 0.53 \\
\hline $\begin{array}{l}\text { Item 18: Which emotions teachers often experience in } \\
\text { interactions with students }\end{array}$ & 0.31 & 0.45 \\
\hline $\begin{array}{l}\text { Item 21: How ideas or thoughts about an individual student } \\
\text { can influence my pedagogical behavior }\end{array}$ & 0.38 & 0.25 \\
\hline $\begin{array}{l}\text { Item 11: What a relationship characterized by closeness, } \\
\text { conflict or dependency looks like }\end{array}$ & 0.21 & 0.33 \\
\hline Item 19: Why coping with their own negative emotions & 0.27 & 0.33 \\
\hline
\end{tabular}
requires energy from teachers

Factor loadings above 0.40 are in bold.

All knowledge items start with "I understand. ..."

applied with caution. Reliability analysis was performed on the complete data set $(N=535)$ to examine the internal consistency of the six factors ${ }^{5}$. Descriptive statistics for each scale and correlations between scales are summarized in Table 9.

First, the exploratory one-factor model for affect-motivation as presented in Table $5\left(\chi^{2}=36.87, d f=44\right.$, CFI $=1.00$, $\mathrm{TLI}=1.00, \mathrm{RMSEA}=0.00(90 \% \mathrm{CI}[0.00,0.03]), \mathrm{SRMR}=0.05)$ showed acceptable fit. The corresponding scale attitude toward teacher-student relationships ( 11 items, $\omega=0.82, \alpha=0.81$, e.g., "Each student deserves a personal relationship with the teacher") represented a positive attitude toward teacherstudent relationships and motivation to invest in building these relationships.

Second, the exploratory two-factor model for knowledge as presented in Table 6 showed acceptable fit $(\chi 2=118.51, d f=89$, CFI $=0.99$, TLI $=0.99$, RMSEA $=0.03(90 \%$ CI $[0.01,0.04])$, SRMR = 0.06). However, interpretation of these factors was

${ }^{5}$ Reliability analysis using only the main study sample yielded similar results, with both $\alpha$ and $\omega$ ranging from 0.82 to 0.85 . 
TABLE 4 | Results of exploratory factor analysis for self-efficacy: factor loadings.

\begin{tabular}{|c|c|c|c|}
\hline Item & \multicolumn{3}{|c|}{ Factor loadings } \\
\hline Item 2: Can get through to each student & 0.58 & -0.12 & 0.04 \\
\hline Item 13: Succeed in building a warm, personal relationship with each student & 0.57 & 0.09 & -0.02 \\
\hline Item 19: Know how to talk with each student about feelings and thoughts & 0.56 & -0.01 & 0.28 \\
\hline Item 15: Can take the perspective of each student & 0.55 & 0.13 & 0.00 \\
\hline Item 1: Know for each student what they need when they are sad & 0.45 & -0.02 & 0.13 \\
\hline Item 5: Obtain a feeling of self-confidence in relation with each student & 0.45 & 0.14 & -0.19 \\
\hline Item 11: Know how to offer emotional security to each student & 0.45 & 0.16 & -0.11 \\
\hline Item 7: Know for each student how to calm them when they are angry or upset & 0.59 & -0.16 & 0.15 \\
\hline Item 9: Can get each student to try new things & 0.41 & 0.22 & 0.05 \\
\hline Item 10: Can react sincerely to each student & -0.10 & 0.54 & -0.06 \\
\hline Item 25: Easily have confidential talks with each student & 0.22 & 0.52 & 0.06 \\
\hline Item 22: Can understand the perspective of each student, even when the student is behaving inappropriately or disruptively & 0.20 & 0.50 & -0.02 \\
\hline Item 8: Can almost always react positively to each student & 0.07 & 0.49 & -0.09 \\
\hline Item 28: Get exhausted by conflicts with students & -0.12 & 0.13 & 0.74 \\
\hline Item 30: Are at risk of losing self-control when a certain student disrupts the class & 0.09 & -0.15 & 0.74 \\
\hline Item 26: Have a hard time keeping emotions in check during conflicts with certain students & 0.17 & -0.13 & 0.66 \\
\hline Item 27: Give up after several efforts and stop searching for further strategies to handle disruptive behavior & 0.23 & -0.30 & 0.63 \\
\hline Item 6: Get exhausted by disruptive student behavior or behavior they cannot control & -0.19 & 0.30 & 0.57 \\
\hline Item 20: Feel attacked or insulted by inappropriate or offensive student behavior & 0.15 & 0.15 & 0.52 \\
\hline
\end{tabular}

Factor loadings above 0.40 are in bold.

All self-efficacy items start with "Some teachers...". Only one pole of the two-pole item is reported. If applicable, items were reverse scored so that a high score reflects high competence.

not clear. For instance, item 6 ("I understand the concept resilience") which targeted a teacher-oriented competence loaded together with several student-oriented competencies (e.g., "I understand the function of the teacher as a secure base"). Likewise, item 14 ("I understand how a relationship with a student can be described in terms of control and affiliation") which targeted a student-oriented competence loaded together with items targeting several teacher-oriented competencies (e.g., "I understand which coping skills are efficient when I feel stressed"). Moreover, 3 items were not retained based upon EFA, while we felt these items represented important theoretical concepts. Item 21 ("I understand how ideas or thoughts about an individual student can influence my pedagogical behavior") represented the concept of mental representations guiding everyday interactions and decisions, a central concept within the extended attachment perspective. Item 19 ("I understand why coping with negative emotions requires energy from teachers") related both to the concept of emotional labor and resilience. Finally, item 11 ("I understand what a relationship characterized by closeness, conflict or dependency looks like") represented a widely used and well-validated conceptualization of the teacherstudent relationship. To explore whether the data would support the inclusion of these three items as hypothesized, we continued with an examination of the a priori two-factor model, based on item content (Table 7). This model showed a less ideal but still acceptable fit $(\chi 2=275.27, d f=134$, CFI $=0.98$, TLI $=0.97$, RMSEA $=0.05(90 \%$ CI $[0.04,0.06])$, SRMR $=0.07)$. As interpretation of the factors is also an important criterium to consider (Costello and Osborne, 2005), the a priori solution as presented in Table 7 was chosen. The two resulting knowledge scales reflected on the one hand knowledge of teacher-student relationships (10 items, $\omega=0.86, \alpha=0.86$, e.g., "I understand 
TABLE 5 | Results of confirmatory factor analysis for affect-motivation.

\begin{tabular}{|c|c|c|c|}
\hline & Est. & $\begin{array}{l}\text { Std. } \\
\text { error }\end{array}$ & $\begin{array}{l}\text { Std. } \\
\text { est. }\end{array}$ \\
\hline \multicolumn{4}{|l|}{ Attitude toward teacher-student relationships } \\
\hline $\begin{array}{l}\text { Item 15: As a teacher, I strive to have a personal } \\
\text { relationship with each student in the class }\end{array}$ & 0.50 & 0.03 & 0.70 \\
\hline $\begin{array}{l}\text { Item 4: Personal relationships with students offer me } \\
\text { personal satisfaction }\end{array}$ & 0.42 & 0.03 & 0.66 \\
\hline $\begin{array}{l}\text { Item } 7: \text { I regret when a relationship with a student is } \\
\text { rather impersonal }\end{array}$ & 0.45 & 0.03 & 0.60 \\
\hline $\begin{array}{l}\text { Item 10: Personal relationships with students are my } \\
\text { number one priority }\end{array}$ & 0.47 & 0.03 & 0.59 \\
\hline $\begin{array}{l}\text { Item 2: Each student deserves a personal relationship } \\
\text { with their teacher }\end{array}$ & 0.43 & 0.03 & 0.59 \\
\hline $\begin{array}{l}\text { Item 14: I want to be a teacher who understands every } \\
\text { student in their class through and through }\end{array}$ & 0.32 & 0.03 & 0.49 \\
\hline $\begin{array}{l}\text { Item 9: Relationships with students can teach me } \\
\text { something about who I am }\end{array}$ & 0.28 & 0.03 & 0.44 \\
\hline $\begin{array}{l}\text { Item 12: I am motivated to understand how personal } \\
\text { relationships with students can touch me personally }\end{array}$ & 0.24 & 0.02 & 0.43 \\
\hline $\begin{array}{l}\text { Item 3: A personal relationship with a student is } \\
\text { important, but not crucial for the quality of education }\end{array}$ & -0.48 & 0.04 & -0.53 \\
\hline $\begin{array}{l}\text { Item 18: Teachers have a rather small impact on a } \\
\text { personal relationship with a student }\end{array}$ & -0.32 & 0.03 & -0.48 \\
\hline $\begin{array}{l}\text { Item 5: Teachers cannot do much when they } \\
\text { experience problems in personal relationships with } \\
\text { students }\end{array}$ & -0.32 & 0.03 & -0.44 \\
\hline
\end{tabular}

$p<0.001$ for all factor loadings.

how a teacher can function as a secure base"), and on the other hand knowledge of coping ( 8 items, $\omega=0.82, \alpha=0.82$, e.g., "I understand how I can cope with the daily emotions and stress I experience in the classroom").

Third, the exploratory three-factor model for self-efficacy as presented in Table 8 showed acceptable fit $\left(\chi^{2}=318.66\right.$, $d f=272$, CFI $=0.99$, TLI $=0.98$, RMSEA $=0.03(90 \% \mathrm{CI}$ $[0.01,0.04])$, SRMR $=0.08)$. The three-factor model fit the data substantially better compared to the a priori two-factor model based on item content $\left(\chi^{2}=1919.46, d f=463\right.$, CFI $=0.69$, TLI $=0.67$, RMSEA $=0.13(90 \%$ CI $[0.12,0.13])$, SRMR $=0.14)$. Therefore, the three-factor solution was chosen. The three corresponding self-efficacy scales represented building closeness (11 items, $\omega=0.83, \alpha=0.83$, e.g., knowing what a child needs when it is sad); coping with conflict (6 items, $\omega=0.82, \alpha=0.82$, e.g., keeping your cool when a child disturbs the lesson); and reflective functioning ( 8 items, $\omega=0.81, \alpha=0.81$, e.g., reflecting upon your emotions toward a specific child). All subscales were positively correlated with all other scales, with the exception of coping with conflict, which was not correlated with building closeness nor with reflective functioning (Table 9).

\section{Criterion Validity}

First, as Table 10 displays, all COMMIT subscales were positively and significantly correlated with relational self-efficacy ( $r$ from 0.26 to $0.45, p<0.001$ ) as well as with general teacher self-efficacy ( $r$ s from 0.16 to $0.44, p<0.001$ ). All COMMIT subscales except coping with conflict were positively correlated with academic selfconcept ( $r$ from 0.11 to $0.20, p<0.05$ ).
TABLE 6 | Results of confirmatory factor analysis for knowledge: EFA solution.

$\begin{array}{rll}\text { Est. Std. Std. } & \text { Std. } \\ \text { error est. }\end{array}$

\section{Knowledge EFA factor 1}

Item 17: How behavioral problems can be an expression of emotional insecurity

$\begin{array}{lllll}\text { Item 20: Why a warm, personal relationship is important } & 0.50 & 0.02 & 0.67\end{array}$ for students' academic achievement

Item 9: Function of the teacher as a secure base $\quad \begin{array}{llll}0.63 & 0.03 & 0.66\end{array}$

Item 10: How a personal relationship with a student $\quad \begin{array}{llll}0.52 & 0.02 & 0.66\end{array}$

influences me as a teacher

Item 16: How authoritarian teacher behavior elicits $\quad \begin{array}{llll}0.63 & 0.03 & 0.63\end{array}$

defiant student behavior

$\begin{array}{lllll}\text { Item 12: How a relationship can be strengthened } & 0.64 & 0.03 & 0.62\end{array}$

through supporting the students' need for competence,

belonging, and autonomy

Item 15: How friendly teacher behavior elicits friendly $\begin{array}{llll}0.48 & 0.02 & 0.62\end{array}$

student behavior

Item 4: Why a warm, personal relationship is important $\quad \begin{array}{llll}0.51 & 0.02 & 0.58\end{array}$

for exploration and motivation of students

$\begin{array}{llll}\text { Item 6: Resilience } & 0.63 & 0.03 & 0.56\end{array}$

Item 2: Emotional security

Knowledge EFA factor 2

Item 14: How a relationship with a student can be $\quad \begin{array}{llll}0.88 & 0.03 & 0.77\end{array}$ described in terms of control and affiliation

Item 18: Which emotions teachers often experience in $\begin{array}{llll}0.71 & 0.03 & 0.76\end{array}$ interactions with students

Item 13: Which coping skills are efficient when I feel $\quad \begin{array}{llll}0.84 & 0.03 & 0.66\end{array}$ stressed

Item 22: How I can effectively cope with emotions and $\quad \begin{array}{llll}0.71 & 0.03 & 0.64\end{array}$ stress I experience in the classroom

Item 8: Emotional labor

$\begin{array}{lll}0.68 & 0.03 & 0.58\end{array}$

$p<0.001$ for all factor loadings.

All knowledge items start with "I understand...".

Second, all COMMIT subscales were positively and significantly correlated with emotional intelligence. Correlations with other-focused emotional intelligence were stronger than correlations with self-focused emotional intelligence ( $r s$ from 0.23 to $0.37, p<0.001$ compared to $r s$ from 0.05 to 0.24 , not all significant) for all subscales except for coping with conflict which was equally strongly correlated with other-focused and self-focused emotional intelligence ( $r s 0.13$ and $0.29, p<0.01$ compared to rs $0.21, p<0.001$ ).

Third, all COMMIT subscales were positively and significantly correlated with student-oriented and subject matter-oriented teacher beliefs ( $r s$ from 0.10 to $0.31, p<0.05$ ), and student contact and social role job motivations ( $r s 0.16$ to $0.30, p<0.01$ ).

Finally, the COMMIT subscales knowledge of coping, building closeness, coping with conflict and reflective functioning were negatively correlated with depression ( $r$ s from -0.11 to -0.15 , $p<0.05)$.

\section{Perceived Dyadic Relationship-Building Competence of Pre-service Teachers}

Descriptive statistics for each scale are summarized in Table 9. To aid in interpretation, distribution plots for the overall sample are presented in the Supplementary Material. For all subscales 
TABLE 7 | Results of confirmatory factor analysis for knowledge: final solution.

$\begin{array}{ccc}\text { Est. } & \text { Std. Std. } \\ \text { error est. }\end{array}$

Knowledge a priori: Knowledge of

teacher-student relationships

Item 14: How a relationship with a student can be

described in terms of control and affiliation

Item 11: What a relationship characterized by

closeness, conflict or dependency looks like

Item 17: How behavioral problems can be an

expression of emotional insecurity

$\begin{array}{llll}\text { Item 20: Why a warm, personal relationship is important } & 0.48 & 0.02 & 0.64\end{array}$

for students' academic achievement

$\begin{array}{llll}\text { Item 9: Function of the teacher as a secure base } & 0.60 & 0.02 & 0.62\end{array}$

$\begin{array}{llll}\text { Item 12: How a relationship can be strengthened } & 0.64 & 0.02 & 0.62\end{array}$

through supporting the students' need for competence,

belonging, and autonomy

Item 16: How authoritarian teacher behavior elicits $\quad \begin{array}{lll}0.60 & 0.02 & 0.61\end{array}$

defiant student behavior

Item 15: How friendly teacher behavior elicits friendly
$\begin{array}{llll}0.45 & 0.02 & 0.58\end{array}$
student behavior

Item 4: Why a warm, personal relationship is important

for exploration and motivation of students

Item 2: Emotional security

Knowledge a priori: Knowledge of coping

Item 18: Which emotions teachers often experience in interactions with students

Item 10: How a personal relationship with a student

influences me as a teacher

Item 21: How ideas about an individual students can

influence my pedagogical behavior

Item 13: Which coping skills are efficient when I feel

stressed

Item 19: Why coping with negative emotions in the

classroom asks for the teacher's energy

Item 22: How I can effectively cope with emotions and

stress I experience in the classroom

Item 6: Resilience

Item 8: Emotional labor

$\begin{array}{lll}0.80 & 0.03 & 0.70 \\ 0.73 & 0.03 & 0.66 \\ 0.58 & 0.02 & 0.65 \\ 0.48 & 0.02 & 0.64 \\ 0.60 & 0.02 & 0.62 \\ 0.64 & 0.02 & 0.62\end{array}$

TABLE 8 | Results of confirmatory factor analysis for self-efficacy.

\begin{tabular}{rccc}
\hline Est. & Std. Std. \\
error est.
\end{tabular}

\section{Building closeness}

Item 19: Know how to talk with each student about feelings and thoughts

Item 15: Can take the perspective of each student

Item 13: Succeed in building a warm, personal

relationship with each student

Item 2: Can get through to each student

Item 14: Are aware of the interests, values, feelings,

ideas, and goals of each student

Item 11: Know how to offer emotional security to each student

Item 7: Know for each student how to calm them when

they are angry or upset

Item 1: Know for each student what they need when they are sad

Item 3: Can talk with each student about feelings and experiences

Item 9: Can get each student to try new things

Item 5: Obtain a feeling of self-confidence in relation

with each student

\section{Coping with conflict}

$\begin{array}{llll}\text { Item 26: Have a hard time keeping emotions in check } & 1.16 & 0.07 & 0.78\end{array}$

during conflicts with certain students

$\begin{array}{llll}\text { Item 27: Give up after several efforts and stop searching } & 1.11 & 0.07 & 0.77\end{array}$

for further strategies to handle disruptive behavior

Item 28: Get exhausted by conflicts with students

Item 30: Are at risk of losing self-control when a certain

student disrupts the class

Item 20: Feel attacked or insulted by inappropriate or

offensive student behavior

Item 6: Get exhausted by disruptive student behavior or

behavior they cannot control

\section{Reflective functioning}

Item 22: Can understand the perspective of each

student, even when the student is behaving

inappropriately or disruptively

Item 32: Frequently reflect on the positive and negative

emotions they experience in interactions with disruptive

students

Item 23: Frequently reflect on thoughts and ideas about individual students and how these impact their behavior Item 25: Easily have confidential talks with each student Item 31: Frequently reflect on the positive and negative emotions they experience in conflicts with individual students

either the distribution was skewed to the left or the center of the distribution was located to the right side of the scale. This indicated that the majority of pre-service teachers had a positive attitude toward teacher-student relationships, felt knowledgeable about teacher-student relationships and coping, and felt rather self-efficacious with regard to building closeness, coping with conflict and reflective functioning. However, an important group felt less competent or even incompetent with regard to knowledge of coping, building closeness and coping with conflict.

\section{Mean Differences Between Pre-primary and Primary Education Programs}

Independent samples $t$-tests revealed no mean differences between pre-service teachers in the pre-primary program and pre-service teachers in the primary program in the full sample $(0.18 \leq p \leq 0.97$, see Table 11). When analyzing each cohort separately, we found two mean differences. In the first year
Item 10: Can react sincerely to each student

Item 21: Frequently reflect on the positive and negative emotions they experience in daily interactions with individual students

Item 8: Can almost always react positively to each student

$p<0.001$ for all factor loadings.

For self-efficacy items only one pole of the two-pole item is reported. All self-efficacy items start with "Some teachers...". The coping with conflict items are reverse scored, so that a high score on the scale reflects high competence.

cohort, pre-service teachers in the primary program $(M=4.00)$ felt more self-efficacious with regard to building closeness compared to pre-service teachers in the pre-primary program $[M=3.73, t(227)=-2.22, p=0.03, d=-0.31]$. In the third 
TABLE 9 | Descriptive statistics and correlations between COMMIT subscales.

\begin{tabular}{|c|c|c|c|c|c|c|c|c|c|c|}
\hline Variable & $M(S D)$ & Range & Skewness (SD) & Kurtosis $(S D)$ & 1. & 2. & 3. & 4. & 5. & 6. \\
\hline 1. Attitude toward teacher-student relationships & $3.92(0.43)$ & $2.44-5.00$ & $-0.13(0.11)$ & $0.02(0.21)$ & - & & & & & \\
\hline 2. Knowledge of teacher-student relationships & $3.81(0.63)$ & $1.40-5.00$ & $-0.40(0.11)$ & $-0.03(0.21)$ & $0.39^{\star \star \star}$ & - & & & & \\
\hline 3. Knowledge of coping & $3.45(0.70)$ & $1.50-5.00$ & $-0.20(0.11)$ & $-0.31(0.21)$ & $0.30^{\star \star \star}$ & $0.82^{\star \star \star}$ & - & & & \\
\hline 4. Building closeness & $3.91(0.90)$ & $1.64-6.00$ & $-0.05(0.11)$ & $-0.53(0.22)$ & $0.26^{\star \star \star}$ & $0.33^{\star \star \star}$ & $0.38^{\star \star \star}$ & - & & \\
\hline 5. Coping with conflict & $3.86(1.02)$ & $1.00-6.00$ & $-0.27(0.11)$ & $-0.52(0.22)$ & $0.13^{\star \star}$ & $0.19^{\star \star \star}$ & $0.10^{\star}$ & -0.08 & - & \\
\hline 6. Reflective functioning & $4.54(0.76)$ & $1.63-6.00$ & $-0.88(0.11)$ & $1.01(0.22)$ & $0.32^{\star \star \star}$ & $0.36^{\star \star \star}$ & $0.28^{\star \star \star}$ & $0.51^{\star \star \star}$ & 0.08 & - \\
\hline
\end{tabular}

${ }^{*} p<0.05,{ }^{* *} p<0.01,{ }^{* * *} p<0.001$.

TABLE 10 | Correlations between COMMIT subscales and related measures.

\begin{tabular}{|c|c|c|c|c|c|c|c|}
\hline Variable & $M(S D)$ & $\begin{array}{l}\text { Attitude toward } \\
\text { teacher-student } \\
\text { relationships }\end{array}$ & $\begin{array}{l}\text { Knowledge of } \\
\text { teacher-student } \\
\text { relationships }\end{array}$ & $\begin{array}{l}\text { Knowledge of } \\
\text { coping }\end{array}$ & $\begin{array}{l}\text { Building } \\
\text { closeness }\end{array}$ & $\begin{array}{l}\text { Coping with } \\
\text { conflict }\end{array}$ & $\begin{array}{l}\text { Reflective } \\
\text { functioning }\end{array}$ \\
\hline \multicolumn{8}{|l|}{$\begin{array}{l}\text { Teacher self-efficacy and } \\
\text { competence }\end{array}$} \\
\hline Relational self-efficacy & $3.89(0.47)$ & $0.38^{\star \star \star}$ & $0.42^{\star \star \star}$ & $0.37^{\star \star \star}$ & $0.39^{\star \star \star}$ & $0.26^{\star \star \star}$ & $0.45^{\star \star \star}$ \\
\hline Instructional strategies & $6.53(0.97)$ & $0.20^{\star \star \star}$ & $0.44^{\star \star \star}$ & $0.43^{\star \star \star}$ & $0.35^{\star \star \star}$ & $0.23^{\star \star \star}$ & $0.30^{\star \star \star}$ \\
\hline Classroom management & $6.57(1.12)$ & $0.16^{\star \star \star}$ & $0.36^{\star \star \star}$ & $0.40^{\star \star \star}$ & $0.34^{\star \star \star}$ & $0.25^{\star \star \star}$ & $0.26^{\star \star \star}$ \\
\hline Student engagement & $6.91(1.04)$ & $0.26^{\star \star \star}$ & $0.43^{\star \star \star}$ & $0.40^{\star \star \star}$ & $0.38^{\star \star \star}$ & $0.20^{\star \star \star}$ & $0.36^{\star \star \star}$ \\
\hline Academic self-concept & $2.40(0.30)$ & $0.12^{*}$ & $0.20^{\star \star \star}$ & $0.13^{\star \star}$ & $0.14^{\star \star}$ & 0.04 & $0.15^{\star \star}$ \\
\hline \multicolumn{8}{|l|}{ Emotional intelligence } \\
\hline Self-focused emotion appraisal & $3.62(0.67)$ & $0.10^{\star}$ & $0.23^{\star \star \star}$ & $0.24^{\star \star \star}$ & $0.21^{\star \star \star}$ & $0.21^{\star \star \star}$ & $0.23^{\star \star \star}$ \\
\hline Other-focused emotion appraisal & $3.91(0.54)$ & $0.33^{\star \star \star}$ & $0.37^{\star \star \star}$ & $0.30^{\star \star \star}$ & $0.29^{\star \star \star}$ & $0.19^{\star \star \star}$ & $0.30^{\star \star \star}$ \\
\hline Self-focused emotion regulation & $3.50(0.67)$ & 0.05 & $0.19^{\star \star \star}$ & $0.19^{\star \star \star}$ & $0.16^{\star \star \star}$ & $0.21^{\star \star \star}$ & $0.10^{*}$ \\
\hline Other-focused emotion regulation & $3.63(0.54)$ & $0.29^{\star \star \star}$ & $0.32^{\star \star \star}$ & $0.30^{\star \star \star}$ & $0.23^{\star \star \star}$ & $0.13^{* *}$ & $0.29^{\star \star \star}$ \\
\hline \multicolumn{8}{|l|}{ Teacher affect-motivation } \\
\hline Subject-matter orientation & $3.26(0.49)$ & $0.21^{\star \star \star}$ & $0.21^{\star \star \star}$ & $0.25^{\star \star \star}$ & $0.21^{\star \star \star}$ & $0.10^{\star}$ & $0.22^{\star \star \star}$ \\
\hline Student orientation & $3.53(0.44)$ & $0.31^{\star \star \star}$ & $0.26^{\star \star \star}$ & $0.20^{\star \star \star}$ & $0.12^{*}$ & $0.17^{\star \star \star}$ & $0.29^{\star \star \star}$ \\
\hline Student contact motivation & $4.31(0.59)$ & $0.30^{\star \star \star}$ & $0.28^{\star \star \star}$ & $0.25^{\star \star \star}$ & $0.20^{\star \star \star}$ & $0.17^{\star \star \star}$ & $0.26^{\star \star \star}$ \\
\hline Social role motivation & $4.27(0.64)$ & $0.19^{\star \star \star}$ & $0.26^{\star \star \star}$ & $0.30^{\star \star \star}$ & $0.20^{\star \star *}$ & $0.16^{\star \star \star}$ & $0.16^{\star \star}$ \\
\hline \multicolumn{8}{|l|}{ Well-being } \\
\hline Depression & $2.21(0.58)$ & 0.06 & -0.08 & $-0.11^{\star}$ & $-0.13^{\star \star}$ & $-0.11^{*}$ & $-0.15^{\star \star \star}$ \\
\hline
\end{tabular}

${ }^{*} p<0.05,{ }^{* *} p<0.01,{ }^{* *} p<0.001$.

year cohort, pre-service teachers in the pre-primary program ( $M=4.33)$ felt more self-efficacious with regard to building closeness compared to pre-service teachers in the primary program $[M=3.78 t(152)=3.72, p<0.001, d=0.61]$. No other within-cohort differences between pre-service teachers in the pre-primary program and pre-service teachers in the primary program were found $(0.07 \leq p \leq 0.92$, see Table 11).

\section{Differences Between Pre-service Teachers Throughout Teacher Training}

We explored cohort differences between pre-service teachers in the first, second and third year of their teacher training (1) in the full sample and (2) for pre-primary and primary teachers separately. Descriptive statistics are summarized in Table 12. Results of ANOVA and post hoc tests for the pre-primary and primary program are reported in Tables 13, 14.

First, with regard to attitude toward teacher-student relationships we found statistically significant differences in the total sample $\left[F(2,528)=12.00, p<0.001, \eta^{2}=0.04\right]$. Post hoc test revealed that pre-service teachers in the third year showed a more positive attitude $(M=4.05)$ compared to pre-service teachers in the first $(M=3.84, p<0.001, d=0.48)$ and second year $(M=3.93, p=0.05, d=0.28)$. There was no significant difference between pre-service teachers in the first and second year $(p=0.12)$. When analyzing pre-primary and primary programs separately, we found a significant difference for pre-primary teachers only (see Tables 13, 14). Pre-service teachers in the third year of the pre-primary program showed a more positive attitude $(M=4.10)$ compared to teachers in the first $(M=3.83, p<0.001, d=0.61)$ and second year $(M=3.93$, $p=0.02, d=0.41)$. There was no statistically significant difference between pre-service teachers in the first and second year $(p=0.13)$ of the pre-primary program.

Second, with regard to knowledge of teacher-student relationships we found significant differences in the total sample $\left[F(2,517)=22.44, p<0.001, \eta^{2}=0.08\right]$. Post hoc test revealed that pre-service teachers in the third year reported more knowledge of teacher-student relationships $(M=4.08)$ compared to pre-service teachers in the first $(M=3.66, p<0.001, d=0.69)$ and second year $(M=3.77, p<0.001, d=0.54)$. There was no 
TABLE 11 | Comparison of pre-service teachers in the pre-primary or in the primary program: independent samples $t$-tests.

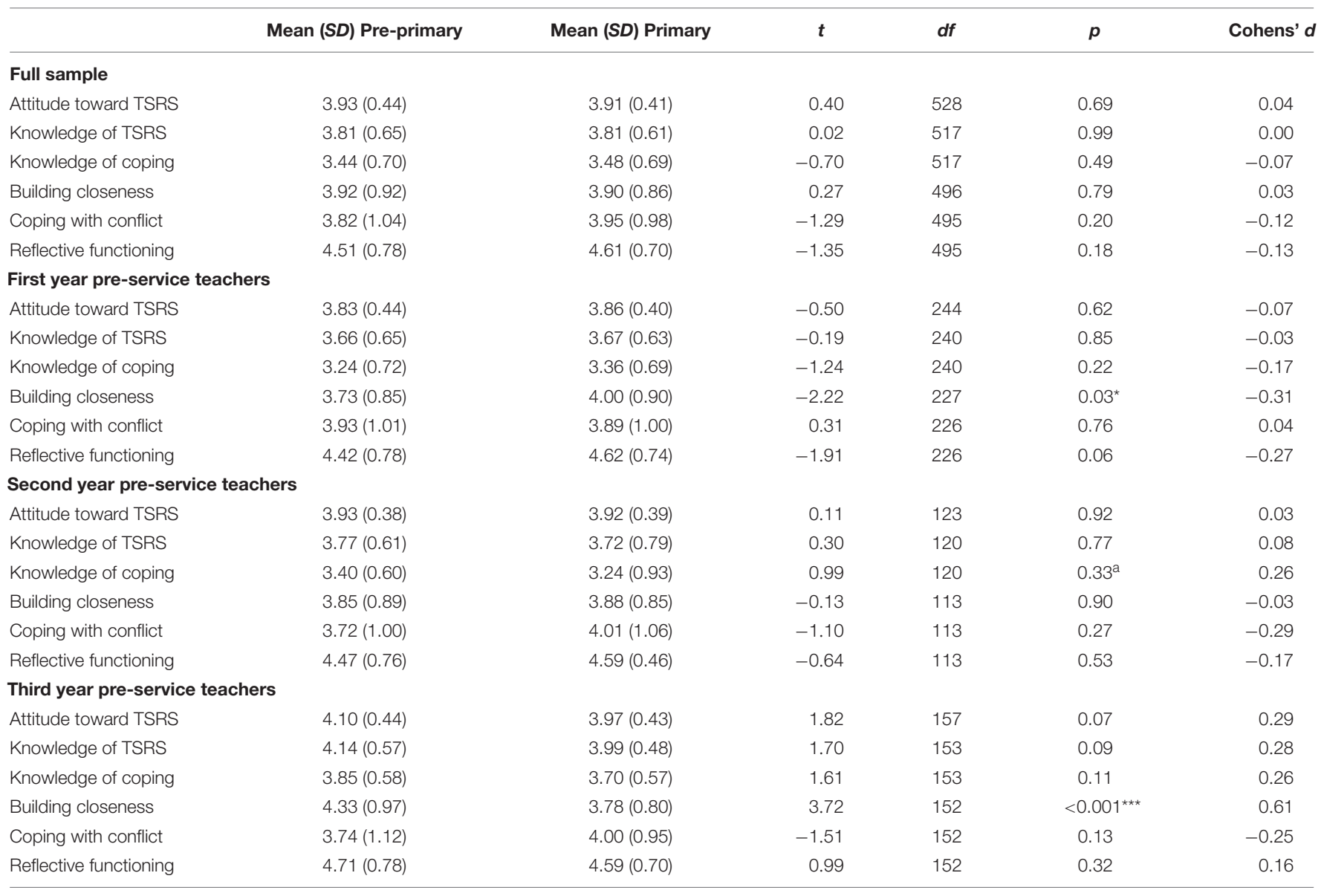

Student's t-test.

${ }^{*} p<0.05,{ }^{* *} p<0.001$

a Levene's test is significant $(p<0.05)$, suggesting a violation of the equal variance assumption.

statistically significant difference between pre-service teachers in the first and second year $(p=0.27)$. This difference was found for both pre-primary and primary programs.

Third, with regard to knowledge of coping we found significant differences in the total sample $[F(2,517)=22.44, p<0.001$, $\left.\eta^{2}=0.10\right]$. Post hoc test revealed that pre-service teachers in the third year reported more knowledge of coping $(M=3.78)$ compared to pre-service teachers in the first $(M=3.27$, $p<0.001, d=0.76)$ and second year $(M=3.38, p<0.001$, $d=0.65)$. There was no statistically significant difference between pre-service teachers in the first and second year $(p=0.32)$. We found this difference for both pre-primary and primary programs.

Fourth, with regard to self-efficacy in building closeness we found significant differences in the total sample $[F(2,496)=4.96$, $\left.p=0.007, \eta^{2}=0.02\right]$. Post hoc test revealed that pre-service teachers in the third year felt more efficient in building closeness $(M=4.10)$ compared to pre-service teachers in the first year $(M=3.85, p=0.007, d=0.31)$. There were no statistically significant differences between pre-service teachers in the first and second year $(p=0.94)$, and the second and third year $(p=0.06)$. Notably, when analyzing data for each program separately, we found differences in self-efficacy in building closeness for the pre-primary program only (see Table 13). Preservice teachers in the third year of the pre-primary program felt more competent in building closeness $(M=4.33)$ compared to teachers in the first $(M=3.73, p<0.001, d=0.67)$ and second year $(M=3.85, p<0.001, d=0.52)$. There was no statistically significant difference between pre-service teachers in the first and second year $(p=0.56)$ of the preprimary program.

Finally, in the total sample we found no differences with regard to self-efficacy in coping with conflict $[F(2,496)=0.81, p=0.44]$ and self-efficacy in reflective functioning $[F(2,495)=2.86$, $p=0.06]$. We did find small differences in self-efficacy in reflective functioning for the pre-primary program when analyzing this data separately (see Table 13). Pre-service teachers in the third year of the pre-primary program $(M=4.75)$ felt more competent compared to teachers in the first year $(M=4.42, p=0.01$, $d=0.37)$. There were no significant differences between teachers in the first and second year $(p=0.87)$, and teachers in the second and third year $(p=0.09)$. 
TABLE 12 | Descriptive statistics for each year of teacher training.

\begin{tabular}{|c|c|c|c|c|}
\hline & \multirow[b]{2}{*}{$\begin{array}{c}\text { Year of } \\
\text { program }\end{array}$} & \multicolumn{3}{|c|}{ Mean (SD) } \\
\hline & & $\begin{array}{l}\text { Overall } \\
\text { sample }\end{array}$ & Pre-primary & Primary \\
\hline \multirow[t]{3}{*}{ Attitude toward TSRS } & 1 & $3.84(0.43)$ & $3.83(0.44)$ & $3.86(0.40)$ \\
\hline & 2 & $3.93(0.38)$ & $3.93(0.38)$ & $3.92(0.39)$ \\
\hline & 3 & $4.05(0.44)$ & $4.10(0.44)$ & $3.97(0.43)$ \\
\hline \multirow[t]{3}{*}{ Knowledge of TSRS } & 1 & $3.66(0.64)$ & $3.66(0.65)$ & $3.67(0.63)$ \\
\hline & 2 & $3.77(0.63)$ & $3.77(0.61)$ & $3.72(0.79)$ \\
\hline & 3 & $4.08(0.53)$ & $4.14(0.57)$ & $3.99(0.48)$ \\
\hline \multirow[t]{3}{*}{ Knowledge of coping } & 1 & $3.28(0.71)$ & $3.24(0.72)$ & $3.36(0.69)$ \\
\hline & 2 & $3.38(0.66)$ & $3.40(0.60)$ & $3.24(0.93)$ \\
\hline & 3 & $3.78(0.58)$ & $3.85(0.58)$ & $3.70(0.57)$ \\
\hline \multirow[t]{3}{*}{ Building closeness } & 1 & $3.82(0.87)$ & $3.73(0.85)$ & $4.00(0.90)$ \\
\hline & 2 & $3.85(0.88)$ & $3.85(0.89)$ & $3.88(0.85)$ \\
\hline & 3 & $4.10(0.94)$ & $4.33(0.97)$ & $3.78(0.80)$ \\
\hline \multirow[t]{3}{*}{ Coping with conflict } & 1 & $3.92(1.00)$ & $3.93(1.01)$ & $3.89(1.00)$ \\
\hline & 2 & $3.77(1.01)$ & $3.72(1.00)$ & $4.01(1.06)$ \\
\hline & 3 & $3.86(1.06)$ & $3.74(1.12)$ & $4.00(0.95)$ \\
\hline \multirow[t]{3}{*}{ Reflective functioning } & 1 & $4.49(0.78)$ & $4.42(0.78)$ & $4.62(0.74)$ \\
\hline & 2 & $4.48(0.73)$ & $4.47(0.76)$ & $4.59(0.46)$ \\
\hline & 3 & $4.66(0.75)$ & $4.71(0.78)$ & $4.59(0.70)$ \\
\hline
\end{tabular}

\section{DISCUSSION}

Seeking an in-depth understanding of teachers' perceived competence in dyadic relationship-building and aiming to explore differences between pre-service teachers in different phases of their teacher education, we developed the Competence Measure of Individual Teacher-student relationships (COMMIT) and administered this new questionnaire in a sample of pre-service teachers in pre-primary and primary teacher education programs. Results showed that the COMMIT measured pre-service teachers' perceived competence in dyadic relationship-building reliably. Based on factor analyses, six scales were retained. Regarding criterion validity, all subscales were significantly and positively correlated with relational self-efficacy, general teacher self-efficacy, emotional intelligence, teacher beliefs, and job motivations. Comparisons between cohorts of pre-service teachers in the first, second and third year of initial teacher education revealed that pre-service teachers in the third (and final) year feel more competent compared to cohorts in the first and second year, yet not in all aspects of dyadic relationship-building. Moreover, these differences were more pronounced for pre-service teachers in the pre-primary program as compared to teachers in the primary program.

\section{Development of the Competence Measure of Individual Teacher-Student Relationships}

The current study aimed to deepen the knowledge on relationship-building competence by focusing on teachers' competence in building dyadic teacher-student relationships. Inspired by the multidimensional conceptualization of teacher competence, including teachers' affect-motivation, knowledge and self-efficacy beliefs (Baumert and Kunter, 2013; Blömeke and Kaiser, 2017), a new measure was developed. Based on exploratory and confirmatory factor analyses, six reliable subscales were formed: attitude toward teacher-student relationships, knowledge of teacher-student relationships, knowledge of coping, and self-efficacy in building closeness, in coping with conflict, and in reflective functioning.

First, the attitude scale represented pre-service teachers' positive attitudes toward and beliefs about the importance of teacher-student relationships for each child. Moreover, this unidimensional scale also reflected the teachers' sense of satisfaction with, responsibility for and motivation to invest in building these relationships, which aligns with the Scandinavian conceptualization of relational competence (Vidmar and Kerman, 2016; Aspelin and Jonsson, 2019). Second, building upon our a priori expectations, we retained two knowledge scales. Knowledge of teacher-student relationships mainly targeted a theoretical understanding of these relationships, based on related theories and constructs, whereas knowledge of coping mainly targeted a theoretical understanding of emotional experiences in relationships with individual children and coping. Finally, instead of the anticipated two subscales, we retained three subscales for self-efficacy. The distinction between the first two subscales, self-efficacy in building closeness and self-efficacy in coping with conflict, corresponds well to research identifying closeness and conflict as two distinguished dimensions of the teacher-student relationship (Sabol and Pianta, 2012; Verschueren and Koomen, 2012). Further research

TABLE 13 | ANOVA results for pre-primary and primary programs.

\begin{tabular}{|c|c|c|c|c|c|c|c|c|c|c|}
\hline & \multicolumn{5}{|c|}{ Pre-primary programs } & \multicolumn{5}{|c|}{ Primary programs } \\
\hline & $d f$ & MS & $\boldsymbol{F}$ & $\eta$ & $p$ & $d f$ & MS & $F$ & $\eta$ & $p$ \\
\hline Knowledge of TSRS & 2 & 6.78 & 17.86 & 0.09 & $<0.001^{\star \star \star}$ & 2 & 1.87 & 5.35 & 0.06 & $0.006^{\star \star}$ \\
\hline Knowledge of coping & 2 & 10.81 & 25.08 & 0.12 & $<0.001^{\star \star \star}$ & 2 & 2.62 & 5.78 & 0.07 & $0.003^{\star \star}$ \\
\hline Building closeness & 2 & 10.41 & 13.07 & 0.07 & $<0.001^{\star \star *}$ & 2 & 0.84 & 1.15 & 0.01 & 0.32 \\
\hline
\end{tabular}

${ }^{*} p<0.05,{ }^{* *} p<0.01,{ }^{* * *} p<0.001$. 
TABLE 14 | Post hoc comparisons for pre-primary and primary programs.

\begin{tabular}{|c|c|c|c|c|c|c|c|c|c|}
\hline & \multirow[b]{2}{*}{ Year of program } & \multicolumn{4}{|c|}{ Pre-primary } & \multicolumn{4}{|c|}{ Primary } \\
\hline & & Mean difference (SD) & $t$ & Cohen's d & $p$ & Mean difference (SD) & $t$ & Cohen's d & $p$ \\
\hline \multirow[t]{3}{*}{ Attitude toward TSRS } & 1 vs. 2 & $-0.10(0.05)$ & -1.94 & 0.24 & 0.13 & & & & \\
\hline & 1 vs. 3 & $-0.27(0.05)$ & -4.92 & 0.61 & $<0.001^{\star \star \star}$ & & & & \\
\hline & 2 vs. 3 & $-0.17(0.06)$ & -2.80 & 0.41 & $0.02^{*}$ & & & & \\
\hline \multirow[t]{3}{*}{ Knowledge of TSRS } & 1 vs. 2 & $-0.12(0.08)$ & -1.51 & 0.18 & 0.29 & $-0.05(0.16)$ & -0.32 & 0.08 & 0.95 \\
\hline & 1 vs. 3 & $-0.48(0.08)$ & -5.93 & 0.78 & $<0.001^{* \star *}$ & $-0.32(0.10)$ & -3.21 & 0.56 & $0.004^{\star \star}$ \\
\hline & 2 vs. 3 & $-0.36(0.09)$ & -4.11 & 0.62 & $<0.001^{* \star *}$ & $-0.27(0.16)$ & -1.66 & 0.48 & 0.22 \\
\hline \multirow[t]{3}{*}{ Knowledge of coping } & 1 vs. 2 & $-0.17(0.08)$ & -2.06 & 0.25 & 0.10 & $0.12(0.18)$ & 0.68 & 0.17 & 0.78 \\
\hline & 1 vs. 3 & $-0.61(0.09)$ & -7.06 & 0.90 & $<0.001^{\star \star \star}$ & $-0.34(0.11)$ & -3.00 & 0.53 & $0.009^{\star \star}$ \\
\hline & 2 vs. 3 & $-0.44(0.09)$ & -4.66 & 0.74 & $<0.001^{\star \star \star}$ & $-0.46(0.18)$ & -2.51 & 0.70 & $0.03^{*}$ \\
\hline \multirow[t]{3}{*}{ Building closeness } & 1 vs. 2 & $-0.12(0.12)$ & -1.02 & 0.14 & 0.56 & & & & \\
\hline & 1 vs. 3 & $-0.60(0.12)$ & -5.03 & 0.67 & $<0.001^{\star \star \star}$ & & & & \\
\hline & 2 vs. 3 & $-0.48(0.13)$ & -3.68 & 0.52 & $<0.001^{\star \star \star}$ & & & & \\
\hline \multirow[t]{3}{*}{ Reflective functioning } & 1 vs. 2 & $-0.05(0.10)$ & -0.50 & 0.06 & 0.87 & & & & \\
\hline & 1 vs. 3 & $-0.29(0.10)$ & -2.81 & 0.37 & $0.01^{*}$ & & & & \\
\hline & 2 vs. 3 & $-0.24(0.11)$ & -2.12 & 0.31 & 0.09 & & & & \\
\hline
\end{tabular}

${ }^{*} p<0.05,{ }^{* *} p<0.01,{ }^{* * *} p<0.001$.

P-value adjusted for comparing a family of three. Cohen's d does not correct for multiple comparisons.

is needed to establish whether these self-efficacy subscales are indeed differentially associated with teacher- or student-reported closeness and conflict, respectively. Contrary to our expectations, a third self-efficacy scale emerged, representing reflective functioning, the teachers' ability to reflect both on their own and their students' emotions and cognitions. Reflective functioning was first studied within parent-child relationships and was shown to be predictive of adequate caregiving practices and relationship quality (Slade, 2007; Rostad and Whitaker, 2016; Camoirano, 2017). Similarly, reflective functioning is considered a valuable skill in professional caregiver relationships, such as teacher-student relationships, and expected to be related to teachers' supportive practices (Stacks et al., 2013). Building upon parental reflective functioning intervention research (Slade, 2007), attachment-based interventions targeting teacher-student relationships emphasize the importance of teachers' ability to reflect upon their (implicit) thoughts and emotions (Spilt et al., 2012; Bosman et al., 2021). Moreover, recent research suggests that teacher reflective functioning might protect against teacher burn-out (Dexter and Wall, 2021). Our results show that teachers' self-efficacy in reflective functioning can be distinguished from self-efficacy in building closeness, which further emphasizes the value of this skill and warrants the need for future research into this concept and its associations with diverse teacher and student outcomes.

The strength of the correlations between the COMMITsubscales varied, which can partly be explained by the diversity of the COMMIT, covering attitudes and perceived knowledge as well as self-efficacy. Correlations between scales addressing the same aspect of competence (e.g., the two knowledge scales) were higher compared to correlations between scales addressing separate aspects of competence (e.g., attitude scale with the knowledge scales). Notably, the subscale self-efficacy in coping with conflict showed only low correlations with the other scales and was not significantly correlated with the two other self-efficacy scales. The small correlations between self-efficacy in coping with conflict and other subscales can be understood, as coping with conflict strongly focuses on teacher-oriented competencies, whereas attitude toward teacher-student relationships, knowledge of teacher-student relationships, self-efficacy in building closeness and self-efficacy in reflective functioning put more emphasis on student-oriented competencies. However, one could have expected a stronger association between self-efficacy in coping with conflict and knowledge of coping. The small correlation between these scales might be explained by the difference in item content specificity. Knowledge of coping addresses a general, theoretical knowledge of coping skills and stress regulation, whereas self-efficacy in coping with conflict specifically focuses on how competent teachers feel in response to conflicts with individual students. Alternatively, the small association between the knowledge and self-efficacy scales might reflect the gap between theory and practice (Korthagen, 2010a,b).

To provide first evidence for construct validity, we explored associations between the COMMIT subscales and conceptually related measures of relational and general teacher self-efficacy, emotional intelligence and affect-motivation in a sample of pre-service teachers. Overall, correlations with closely related concepts (relational self-efficacy, general teacher self-efficacy) were stronger compared to correlations with concepts that are further removed from dyadic relationship-building competence (academic self-concept, self-focused emotional intelligence, teacher affect-motivation, and depression). Strength of the associations varied across COMMIT-subscales. As expected, the attitude subscale was more closely associated with teacher affectmotivation (teacher beliefs and job motivations) compared to the knowledge and self-efficacy scales, which were in turn more closely associated with relational and general teacher self-efficacy. 
These results supported discriminant validity of the different COMMIT subscales. The self-efficacy in coping with conflict subscale showed the least strong associations with relational and general teacher self-efficacy. This might be explained by a difference in item content: self-efficacy in coping with conflict emphasizes teacher-oriented competencies (e.g., understanding of emotional experiences and coping), whereas relational and general teacher self-efficacy primarily include student-oriented or caregiving competencies (e.g., support a student emotionally, calm a disruptive student). In line with this difference in focus, self-efficacy in coping with conflict was more strongly associated with self-focused emotional intelligence, whereas self-efficacy in building closeness and self-efficacy in reflective functioning showed a stronger association with other-focused emotional intelligence. Unexpectedly, self-efficacy in building closeness was associated with both student-oriented and subject-matter oriented beliefs, but associations with subject-matter oriented teacher beliefs were stronger. Indeed, while some studies showed that student-oriented teacher beliefs are related to closer teacherchild relationships (e.g., Driscoll and Pianta, 2010), others found no significant associations between teacher beliefs and closeness (e.g., Mashburn et al., 2006; Castle et al., 2015).

In sum, these results provided initial evidence that the COMMIT reliably measured the various dimensions of perceived dyadic relationship-building competence and were related to, but could be distinguished from, existing measures of teacher selfefficacy, emotional intelligence, and teacher affect-motivation.

\section{Pre-service Teachers' Average Perceived Competence}

Following development of the COMMIT, we aimed to investigate the level of pre-service teachers' perceived relationship-building competence. Overall, pre-service teachers reported a positive attitude toward teacher-student relationships. They felt quite knowledgeable and held positive self-efficacy beliefs, although not in all aspects of dyadic relationship-building. Pre-service teachers on average felt rather knowledgeable about teacherstudent relationships and efficacious in reflective functioning, while they reported relatively less knowledge of coping and felt relatively less efficacious with regard to coping with conflict and building closeness. As discussed, all three aspects of teachers' (perceived) competence need to be developed in order to be translated into effective practices (Kunter et al., 2013; Spruce and Bol, 2014; Blömeke and Kaiser, 2017; Depaepe and König, 2018). Thus, a positive attitude toward teacher-student relationships and theoretical knowledge about these relationships without a feeling of self-efficacy is not sufficient for teachers to build positive, close relationships with each of their students.

\section{Differences in Perceived Competence Across Years of Teacher Education}

Furthermore, we aimed to explore differences between preservice teachers in different phases of their teacher education on pre-service teachers' perceived dyadic relationship-building competence, by comparing cohorts of pre-service teachers in their first, second, and third (final) year of teacher education. In the overall sample, third-year pre-service teachers held a slightly more positive attitude toward teacher-student relationships, reported more knowledge of teacher-student relationships and coping, and felt more competent with regard to building closeness. However, no overall differences were found with regard to self-efficacy in coping with conflict and in reflective functioning. Notably, these results varied when analyzing the preprimary and primary program separately. Third-year pre-service teachers in the primary program reported more knowledge of teacher-student relationships and coping compared to cohorts of first- and second-year pre-service teachers. No differences in attitude nor in self-efficacy were observed between cohorts in the primary program. In contrast, in the pre-primary program, third-year pre-service teachers reported more knowledge of teacher-student relationships and coping, and additionally held a more positive attitude toward teacher-student relationships and felt more competent with regard to building closeness and reflective functioning compared to first- and second-year preservice teachers. Moreover, these third-year pre-service teachers in the pre-primary program felt more self-efficacious in building closeness compared to their peers in the third year of the primary program.

These differential effects in the pre-primary and primary program reflect a trend in research on teacher-student relationships to focus on early childhood, as compared to middle or late childhood (Verschueren, 2015). This trend might also be present within the curricula of teacher education programs. In both programs, third-year pre-service teachers felt more knowledgeable compared to first- and second-year teachers. However, only third-year pre-primary teachers reported more positive self-efficacy beliefs and a more positive attitude. It is possible that (the importance of) the teacher-student relationship is more often included or emphasized within pre-primary teacher education programs. As students in preprimary schools are younger and their self-regulation abilities less developed, teachers might need to take on the role of caregiver more frequently (whereas gradually more emphasis is put on the instructional role of teachers as children grow older). Teacher education programs might, explicitly or implicitly, be tailored to this difference. However, a positive teacher-student relationship is important for students of all ages, from preprimary to secondary and higher education (e.g., Engels et al., 2016; Roorda et al., 2017; Bosman et al., 2018), as well as for the well-being of all teachers (Evans et al., 2019). Therefore, all teachers should be able to build close relationship with their students, regardless of student age.

Although pre-service teachers in the third year reported more knowledge of coping, no differences were found with regard to self-efficacy in coping with conflict, neither in the overall sample, nor in any of the subgroups. These results can possibly be explained by a lack of attention for teachers' coping skills in the teacher education curriculum or a lack of opportunities to apply these coping skills (Korthagen, 2010a,b). These possible explanations are supported by earlier research on teachers' social emotional learning (SEL). When screening teacher education curricula for the integration of SEL, SchonertReichl et al. (2017) noted that teachers' self-awareness and 
self-management (including an understanding of emotional experiences and coping skills) were only rarely included in teacher education, whereas responsible decision-making, social awareness and general relationship skills (e.g., running an effective meeting; collaborating with parents and colleagues) were integrated in most curricula (Schonert-Reichl et al., 2017). In addition, students' SEL were more often included in the curricula compared to teachers' SEL. When learning about students' SEL, including students' self-awareness and self-management, preservice teachers' general knowledge about coping might increase. However, without the opportunity to apply this knowledge to their own experiences of conflict with students, pre-service teachers' self-efficacy in coping with conflict might not increase. Yet, as discussed, teachers' coping skills are crucial for their well-being as well as their students' wellbeing (Hastings and Brown, 2002; Beltman et al., 2011; Whitaker et al., 2015; McGrath and Van Bergen, 2019). Moreover, the experience of and inability to cope with negative emotions in interactions with students can negatively impact teachers' ability to respond sensitively to their students' needs (Koenen et al., 2019a,b). As pre-service teachers were found to often rely on maladaptive coping strategies (Gustems-Carnicer et al., 2019) and our results showed that almost half of pre-service teachers do not feel competent in coping with conflicts with students, we argue that teacher education curricula should focus more on teacher well-being in teacher-student relationships and address selfawareness, adaptive coping skills, and self-care. A tool that could be used to this end is the intervention LLInC (Leerkracht Leerling Interactie Coaching in Dutch, or Teacher Student Interaction Coaching; Koomen and Spilt, 2010-2017), which has recently been applied and evaluated in teacher education (Koenen et al., 2021). LLInC was delivered to pre-service teachers during their final internship in a specialization year of the education program. LLInC offers guided relationship-focused reflection which helped pre-service teachers to become more aware of the (both positive and negative) emotions they experienced in interactions with students and of the cognitions they had about their relationships with students. This could help them cope with negative emotions and focus on (re)building a positive teacher-student relationship.

Increased attention to teacher stress and well-being from a relationship perspective during initial teacher education would not only benefit pre-service teachers during their teacher training, but can also offer an advantage when they enter the profession (Spilt et al., 2011; Gustems-Carnicer et al., 2019). The majority of teachers who leave the profession attribute their decision to occupational stress, which is often related to stressful interactions with students (Friedman, 1995; de Jonge and de Muijnck, 2002; Liu and Meyer, 2005; Liu and Onwuegbuzie, 2012). Providing starting teachers with the tools to cope with occupational stress in general and interpersonal stress specifically, might increase their chances of staying in the profession. In light of the teacher shortage across several countries (UNESCO, 2015) and the remarkably high attrition of beginning teachers (who leave the profession within the first 5 years) in Flanders specifically (Departement Onderwijs en Vorming, 2013, 2014), it is definitely worthwhile to further investigate the potential of teacher education in supporting teacher well-being from a relationship perspective.

\section{Limitations and Future Directions}

Development of the COMMIT offers new possibilities for future research, although some limitations need to be considered. First, differences between cohorts of teachers in subsequent years of the teacher education program might not be completely attributed to the program itself but rather to differences between the cohorts. No causal conclusions can therefore be drawn about the impact of teacher education based on this cross-sectional study. To further explore the effects of teacher education on teachers' perceived dyadic relationshipbuilding competence, a longitudinal design which follows the progression of a single cohort of students might be more appropriate.

Second, we pointed to differences in the curriculum as a possible explanation for the differential results in the pre-primary and primary teacher education program. An investigation of the curricula might support or refute this hypothesis and offer additional insights into how future teachers are prepared for the relational and emotional challenges they will face in the classroom.

Third, this study focused on pre-service teachers' selfreported, perceived competence and could be complemented by tests of actual relationship-building competence. An instrument that could be used to this end is the TRUST (Aldrup et al., 2020), a situational judgment test which assesses teachers' competence in emotion management (with content largely similar to the coping and reflective functioning scales of the COMMIT) and relationship management (content largely similar to building closeness).

Finally, as this study focused on pre-service teachers, who spent only a limited amount of time with the same students during their practicum, associations with actual relationship quality could not be examined. Validation of the COMMIT in a sample of in-service teachers might offer new insights into the relationship between teachers' perceived competence and (developments in) actual teacher-student relationship quality. In addition, we argued that coping and reflective functioning are crucial skills in teachers' ability to build relationships and inadequate coping and lack of reflection might impact their wellbeing. Although research supports this assumption (Hastings and Brown, 2002; Beltman et al., 2011; Whitaker et al., 2015; McGrath and Van Bergen, 2019), the relevance of self-efficacy in coping with teacher-student conflict specifically (rather than coping with occupational stress in general) and reflective functioning for relationship quality and teachers' well-being should be further investigated. The COMMIT could be used to this end.

In addition to its value in clarifying theoretical issues, the COMMIT could, once predictive validity has been established, be used to evaluate teacher education programs, professional development initiatives or interventions targeting teacher-child relationships, teachers' relational competence or teacher wellbeing. Furthermore, the COMMIT might be used to assess inservice teachers' perceived competence and to signal the need for intervention or targeted professional development. 


\section{CONCLUSION}

In search of a deeper understanding of teachers' perceived competence in dyadic relationship-building, we developed the Competence Measure of Individual Teacher-student relationships (COMMIT). This measure offers new possibilities for future research, including a more in-depth investigation of the attitudes, knowledge and skills that teachers need to build positive teacher-student relationships. Pre-service teachers appeared to have a rather positive attitude toward teacher-student relationships, and felt quite knowledgeable and self-efficacious, yet not in all aspects of dyadic relationship-building. In addition, results revealed that pre-service teachers in the final year of teacher training felt more competent compared to their colleagues in the first and second year, although, again, not for all aspects of dyadic relationship-building. Notably, differences between pre-service teachers in subsequent years of teacher education were less pronounced in primary compared to preprimary teacher education programs. Given the importance of close relationships for both child development and teacher wellbeing, more efforts should be made to prepare teachers to build positive teacher-student relationships.

\section{DATA AVAILABILITY STATEMENT}

The raw data supporting the conclusions of this article will be made available by the authors, without undue reservation.

\section{ETHICS STATEMENT}

The studies involving human participants were reviewed and approved by Social and Societal Ethics Committee of KU Leuven.

\section{REFERENCES}

Aboagye, M. O., Boateng, P., Asare, K., Sekyere, F. O., Antwi, C. O., and Qin, J. (2020). Managing conflictual teacher-child relationship in pre-schools: a preliminary test of the job resources buffering-effect hypothesis in an emerging economy. Child. Youth Serv. Rev. 118:105668. doi: 10.1016/j.childyouth.2020. 105468

Aelterman, A., Meysman, H., Troch, F., Vanlaer, O., and Verkens, A. (2008). Een nieuw profiel voor de leraar kleuteronderwijs en lager onderwijs. Hoe worden leraren daartoe gevormd?. Brussels, Belgium: Departement Onderwijs en Vorming.

Aldrup, K., Carstensen, B., Koller, M. M., and Klusmann, U. (2020). Measuring Teachers' Social-Emotional Competence: development and Validation of a Situational Judgment Test. Front. Psychol. 11:892. doi: 10.3389/fpsyg.2020. 00892

Ansari, A., Hofkens, T. L., and Pianta, R. C. (2020a). Teacher-student relationships across the first seven years of education and adolescent outcomes. J. Appl. Dev. Psychol. 71:101200. doi: 10.1016/j.appdev.2020.101200

Ansari, A., Pianta, R. C., Whittaker, J. V., Vitiello, V. E., and Ruzek, E. A. (2020b). Preschool Teachers' Emotional Exhaustion in Relation to Classroom Instruction and Teacher-child Interactions. Early Educ. Dev. 33, 1-14. doi: 10.1080/10409289.2020.1848301

Aspelin, J., and Jonsson, A. (2019). Relational competence in teacher education. Concept analysis and report from a pilot study. Teach. Dev. 23, 264-283. doi: $10.1080 / 13664530.2019 .1570323$
The patients/participants provided their written informed consent to participate in this study.

\section{AUTHOR CONTRIBUTIONS}

LB coordinated the study, collected and analyzed the data, and wrote the manuscript. JS contributed to the discussion. Both authors contributed to conception, design and methodology of the study, development of the new measure, and reviewed and edited the manuscript.

\section{FUNDING}

This work was supported by Research Foundation Flanders grant 1 SE4921N to LB.

\section{ACKNOWLEDGMENTS}

We would like to thank our partners at Hogeschool WestVlaanderen, Odisee Hogeschool, and University Colleges Leuven for their help in the recruitment of pre-service teachers and feedback on early versions of the questionnaire. We would also like to thank our colleagues, in particular, Anne-Katrien Koenen and Helma Koomen, for their feedback and input on the questionnaire items.

\section{SUPPLEMENTARY MATERIAL}

The Supplementary Material for this article can be found online at: https://www.frontiersin.org/articles/10.3389/feduc. 2022.831468/full\#supplementary-material

Aspelin, J., Östlund, D., and Jönsson, A. (2020). 'It means everything': special educators' perceptions of relationships and relational competence. Eur. J. Spec. Needs Educ. 36, 1-15. doi: 10.1080/08856257.2020.1783801

Aspelin, J., Östlund, D., and Jönsson, A. (2021). Pre-Service Special Educators' Understandings of Relational Competence. Front. Educ. 6:678793. doi: 10.3389/ feduc.2021.678793

Baumert, J., and Kunter, M. (2013). "The COACTIV Model of Teachers' Professional Competence," in Cognitive Activation in the Mathematics Classroom and Professional Competence of Teachers, eds M. Kunter, J. Baumert, W. Blum, U. Klusmann, S. Krauss, and M. Neubrand (Boston, MA: Springer), 25-48. doi: 10.1007/978-1-4614-5149-5_2

Beltman, S., Mansfield, C., and Price, A. (2011). Thriving not just surviving: a review of research on teacher resilience. Educ. Res. Rev. 6, 185-207. doi: 10. 1016/j.edurev.2011.09.001

Blömeke, S., and Kaiser, G. (2017). "Understanding the development of teachers' professional competencies as personally, situationally and socially determined," in The SAGE Handbook of Research on Teacher Education, eds D. J. Clandinin and J. Husu (London, UK: SAGE Publications), 783-802. doi: 10.4135/ 9781529716627

Bosman, R. J., Roorda, D. L., van der Veen, I., and Koomen, H. M. Y. (2018). Teacher-student relationship quality from kindergarten to sixth grade and students' school adjustment: a person-centered approach. J. Sch. Psychol. 68, 177-194. doi: 10.1016/j.jsp.2018.03.006

Bosman, R. J., Zee, M., de Jong, P. F., and Koomen, H. M. Y. (2021). Using relationship-focused reflection to improve teacher-child relationships and 
teachers' student-specific self-efficacy. J. Sch. Psychol. 87, 28-47. doi: 10.1016/ j.jsp.2021.06.001

Buyse, E., Verschueren, K., Doumen, S., Van Damme, J., and Maes, F. (2008). Classroom problem behavior and teacher-child relationships in kindergarten: the moderating role of classroom climate. J. Sch. Psychol. 46, 367-391. doi: 10.1016/j.jsp.2007.06.009

Buyse, E., Verschueren, K., Verachtert, P., and Van Damme, J. (2009). Predicting School Adjustment in Early Elementary School: impact of Relationship Quality and Relational Classroom Climate. Elem. Sch. J. 110, 119-141. doi: 10.1086/ 605768

Camoirano, A. (2017). Mentalizing Makes Parenting Work: a Review about Parental Reflective Functioning and Clinical Interventions to Improve It. Front. Psychol. 8:14. doi: 10.3389/fpsyg.2017.00014

Castle, S., Williamson, A. C., Young, E., Stubblefield, J., Laurin, D., and Pearce, N. (2015). Teacher-Child Interactions in Early Head Start Classrooms: associations With Teacher Characteristics. Early Educ. Dev. 27, 259-274. doi: 10.1080/10409289.2016.1102017

Chang, M.-L., and Davis, H. A. (2009). "Understanding the role of teacher appraisals in shaping the dynamics of their relationship with students: deconstructing teachers' judgements of disruptive behavior/students," in Advances in teacher emotion research: the impact on teachers' lives, eds P. A. Schutz and M. Zembylas (Dordrecht, The Netherlands: Springer), 95-128. doi: 10.1007/978-1-4419-0564-2 6

Charalambous, C. Y. (2015). Working at the intersection of teacher knowledge, teacher beliefs, and teaching practice: a multiple-case study. J. Math. Teach. Educ. 18, 427-445. doi: 10.1007/s10857-015-9318-7

Corbin, C. M., Alamos, P., Lowenstein, A. E., Downer, J. T., and Brown, J. L. (2019). The role of teacher-student relationships in predicting teachers' personal accomplishment and emotional exhaustion. J. Sch. Psychol. 77, 1-12. doi: 10. 1016/j.jsp.2019.10.001

Costello, A. B., and Osborne, J. W. (2005). Best Practices in Exploratory Factor Analysis: four Recommendations for Getting the Most From Your Data. Pract. Assess. 10, 1-9. doi: 10.7275/jyj1-4868

Crosnoe, R., Morrison, F., Burchinal, M., Pianta, R., Keating, D., Friedman, S. L., et al. (2010). Instruction, Teacher-Student Relations, and Math Achievement Trajectories in Elementary School. J. Educ. Psychol. 102, 407-417. doi: 10.1037/ a 0017762

De Cooman, R., De Gieter, S., Pepermans, R., Du Bois, C., Caers, R., and Jegers, M. (2007). Graduate teacher motivation for choosing a job in education. Int. J. Educ. Vocat. Guid. 7, 123-136. doi: 10.1007/s10775-007-9117-5

de Jonge, J. F. M., and de Muijnck, J. A. (2002). Waarom leraren de sector verlaten: onderzoek naar de uitstroom uit het primair en voortgezet onderwijs. Zoetermeer, The Netherlands: EIM: Onderzoek voor Bedrijf en Beleid.

de Ruiter, J. A., Poorthuis, A. M. G., and Koomen, H. M. Y. (2021). Teachers' emotional labor in response to daily events with individual students: the role of teacher-student relationship quality. Teach. Teach. Educ. 107:103467. doi: 10.1016/j.tate.2021.103467

De Smul, M., Heirweg, S., Van Keer, H., Devos, G., and Vandevelde, S. (2018). How competent do teachers feel instructing self-regulated learning strategies? Development and validation of the teacher self-efficacy scale to implement selfregulated learning. Teach. Teach. Educ. 71, 214-225. doi: 10.1016/j.tate.2018. 01.001

de Vries, S., van de Grift, W. J. C. M., and Jansen, E. P. W. A. (2013). How teachers' beliefs about learning and teaching relate to their continuing professional development. Teach. Teach. 20, 338-357. doi: 10.1080/13540602.2013.848521

Deci, E. L., Vallerand, R. J., Pelletier, L. G., and Ryan, R. M. (1991). Motivation and Education: the Self-Determination Perspective. Educ. Psychol. 26, 325-346.

Depaepe, F., and König, J. (2018). General pedagogical knowledge, self-efficacy and instructional practice: disentangling their relationship in pre-service teacher education. Teach. Teach. Educ. 69, 177-190. doi: 10.1016/j.tate.2017.10.003

Departement Onderwijs en Vorming (2013). Beleidsevaluatie lerarenopleidingen: rapport van de Commissie Beleidsevaluatie Lerarenopleiding. [Policy evaluation teacher education: report of the Commission Policy Evaluation Teacher education]. Brussels, Belgium: Departement Onderwijs en Vorming.

Departement Onderwijs en Vorming (2014). Resultaten beleidsgroepen lerarenopleiding. [Results policy groups teacher education programs]. Brussels, Belgium: Departement Onderwijs en Vorming.
Dexter, C. A., and Wall, M. (2021). Reflective functioning and teacher burnout: the mediating role of self-efficacy. Reflective Pract. 22, 753-765. doi: 10.1080/ 14623943.2021.1968817

Driscoll, K. C., and Pianta, R. C. (2010). Banking Time in Head Start: early Efficacy of an Intervention Designed to Promote Supportive Teacher-Child Relationships. Early Educ. Dev. 21, 38-64. doi: 10.1080/10409280802657449

Engels, M. C., Colpin, H., Van Leeuwen, K., Bijttebier, P., Van Den Noortgate, W., Claes, S., et al. (2016). Behavioral Engagement, Peer Status, and TeacherStudent Relationships in Adolescence: a Longitudinal Study on Reciprocal Influences. J. Youth Adolesc. 45, 1192-1207. doi: 10.1007/s10964-016-0414-5

Evans, D., Butterworth, R., and Law, G. U. (2019). Understanding associations between perceptions of student behaviour, conflict representations in the teacher-student relationship and teachers' emotional experiences. Teach. Teach. Educ. 82, 55-68. doi: 10.1016/j.tate.2019.03.008

Flora, D. B., and Flake, J. K. (2017). The purpose and practice of exploratory and confirmatory factor analysis in psychological research: decisions for scale development and validation. Can. J. Behav. Sci. 49, 78-88. doi: 10.1037/ cbs0000069

Friedman, I. A. (1995). Student Behavior Patterns Contributing to Teacher Burnout. J. Educ. Res. 88, 281-289. doi: 10.1080/00220671.1995.9941312

Gable, S. L., and Shean, G. D. (2000). Perceived Social Competence and Depression. J. Soc. Pers. Relat. 17, 139-150. doi: 10.1177/0265407500171007

Germeijs, V., and De Boeck, P. (2002). A Measurement Scale for Indecisiveness and its Relationship to Career Indecision and Other Types of Indecision. Eur. J. Psychol. Assess. 18, 113-122. doi: 10.1027//1015-5759.18.2.113

Gustems-Carnicer, J., Calderón, C., and Calderón-Garrido, D. (2019). Stress, coping strategies and academic achievement in teacher education students. Eur. J. Teach. Educ. 42, 375-390. doi: 10.1080/02619768.2019.1576629

Hagenauer, G., Hascher, T., and Volet, S. E. (2015). Teacher emotions in the classroom: associates with students' engagement, classroom discipline and the interpersonal teacher-student relationship. Eur. J. Psychol. Educ. 30, 385-403. doi: 10.1007/s10212-015-0250-0

Hajovsky, D. B., Chesnut, S. R., and Jensen, K. M. (2020). The role of teachers' self-efficacy beliefs in the development of teacher-student relationships. J. Sch. Psychol. 82, 141-158. doi: 10.1016/j.jsp.2020.09.001

Harter, S. (1982). The Perceived Competence Scale for Children. Child Dev. 53, 87-97. doi: 10.2307/1129640

Hastings, R. P., and Brown, T. (2002). Coping Strategies and the Impact of Challenging Behaviors on Special Educators' Burnout. Ment. Retard. 40, 148156. doi: 10.1352/0047-67652002040<0148:CSATIO<2.0.CO;2

Hayes, A. F., and Coutts, J. J. (2020). Use Omega Rather than Cronbach's Alpha for Estimating Reliability. But.... Commun. Methods Meas. 14, 1-24. doi: 10.1080/ 19312458.2020.1718629

Horzum, T., and Izci, K. (2018). Preservice Turkish Teachers' Views and Perceived Competence Related to Inclusive Education. J. Educ. e-Learn. Res. 5, 131-143. doi: 10.20448/journal.509.2018.52.131.143

Hu, L., and Bentler, P. M. (1999). Cutoff criteria for fit indexes in covariance structure analysis: conventional criteria versus new alternatives. Struct. Equ. Modeling 6, 1-55. doi: 10.1080/10705519909540118

Jensen, E., Skibsted, E. B., and Christensen, M. V. (2015). Educating teachers focusing on the development of reflective and relational competences. Educ. Res. Policy Pract. 14, 201-212. doi: 10.1007/s10671-015-9185-0

Jo, S. H. (2014). Teacher commitment: exploring associations with relationships and emotions. Teach. Teach. Educ. 43, 120-130. doi: 10.1016/j.tate.2014.07.004

Klassen, R. M., Bong, M., Usher, E. L., Chong, W. H., Huan, V. S., Wong, I. Y. F., et al. (2009). Exploring the validity of a teachers' self-efficacy scale in five countries. Contemp. Educ. Psychol. 34, 67-76. doi: 10.1016/j.cedpsych.2008. 08.001

Klassen, R. M., Perry, N. E., and Frenzel, A. C. (2012). Teachers' relatedness with students: an underemphasized component of teachers' basic psychological needs. J. Educ. Psychol. 104, 150-165. doi: 10.1037/a0026253

Koenen, A.-K., Borremans, L. F. N., De Vroey, A., Kelchtermans, G., and Spilt, J. L. (2021). Strengthening Individual Teacher-Child Relationships: an Intervention Study Among Student Teachers in Special Education. Front. Educ. 6:769573. doi: 10.3389/feduc.2021.769573

Koenen, A.-K., Vervoort, E., Kelchtermans, G., Verschueren, K., and Spilt, J. L. (2019a). Teacher sensitivity in interaction with individual students: the role 
of teachers' daily negative emotions. Eur. J. Spec. Needs Educ. 34, 514-529. doi: 10.1080/08856257.2018.1553876

Koenen, A.-K., Vervoort, E., Kelchtermans, G., Verschueren, K., and Spilt, J. L. (2019b). Teachers' daily negative emotions in interactions with individual students in special education. J. Emot. Behav. Disord. 27, 37-51. doi: 10.1177/ 1063426617739579

Koomen, H. M. Y., and Lont, T. A. E. (2004). Teacher Relationship Interview: qualitative coding manual. [Unpublished Dutch Translation]. Netherlands: Universiteit van Amsterdam.

Koomen, H. M. Y., and Spilt, J. L. (yr2010-2017). Leerkracht Leerling Interactie Coaching (LLInC): trainingshandleiding [Unpublished work]. Netherlands: Universiteit van Amsterdam.

Korpershoek, H., Harms, T., de Boer, H., van Kuijk, M., and Doolaard, S. (2016). A meta-analysis of the effects of classroom management strategies and classroom management programs on students' academic, behavioral, emotional, and motivational outcomes. Rev. Educ. Res. 86, 643-680. doi: 10. 3102/0034654315626799

Korthagen, F. A. J. (2010a). How teacher education can make a difference. J. Educ. Teach. 36, 407-423. doi: 10.1080/02607476.2010.513854

Korthagen, F. A. J. (2010b). "The relationship between theory and practice in teacher education," in International Encyclopedia of Education, eds E. Baker, B. McGaw, and P. Peterson (Oxford: Elsevier), 669-675.

Kunter, M., Klusmann, U., Baumert, J., Richter, D., Voss, T., and Hachfeld, A. (2013). Professional competence of teachers: effects on instructional quality and student development. J. Educ. Psychol. 105, 805-820. doi: 10.1037/a0032583

Liu, S., and Onwuegbuzie, A. J. (2012). Chinese teachers' work stress and their turnover intention. Int. J. Educ. Res. 53, 160-170. doi: 10.1016/j.ijer.2012.03.006

Liu, X. S., and Meyer, J. P. (2005). Teachers' Perceptions of Their Jobs: a Multilevel Analysis of the Teacher Follow-Up Survey for 1994-95. Teach. Coll. Rec. 107, 985-1003. doi: 10.1111/j.1467-9620.2005.00501.x

Mashburn, A. J., Hamre, B. K., Downer, J. T., and Pianta, R. C. (2006). Teacher and Classroom Characteristics Associated With Teachers' Ratings of Prekindergartners' Relationships and Behaviors. J. Psychoeduc. Assess. 24, 376-380. doi: 10.1177/0734282906290594

McGrath, K. F., and Van Bergen, P. (2015). Who, when, why and to what end? Students at risk of negative student-teacher relationships and their outcomes. Educ. Res. Rev. 14, 1-17. doi: 10.1016/j.edurev.2014.12.001

McGrath, K. F., and Van Bergen, P. (2019). Attributions and emotional competence: why some teachers experience close relationships with disruptive students (and others don't). Teach. Teach. 25, 334-357. doi: 10.1080/13540602. 2019.1569511

Meade, A. W., and Craig, S. B. (2012). Identifying careless responses in survey data. Psychol. Methods 17, 437-455. doi: 10.1037/a0028085

Mertens, W. (1997). Zelf-concept. Theoretische achtergrond en constructie van een meetinstrument voor leerlingen van het ASO en TSO [Self-concept. Theoretical background and construction of an instrument for students in general and technical secondary education]. Ph.D. thesis. Belgium, Leuven: KU Leuven.

Milatz, A., Luftenegger, M., and Schober, B. (2015). Teachers' Relationship Closeness with Students as a Resource for Teacher Wellbeing: a Response Surface Analytical Approach. Front. Psychol. 6:1949. doi: 10.3389/fpsyg.2015. 01949

Moen, A. L., Sheridan, S. M., Schumacher, R. E., and Cheng, K. C. (2019). Early Childhood Student-Teacher Relationships: what is the Role of Classroom Climate for Children Who are Disadvantaged? Early Child. Educ. J. 47, 331-341. doi: 10.1007/s10643-019-00931-x

Montoya, A. K., and Edwards, M. C. (2020). The Poor Fit of Model Fit for Selecting Number of Factors in Exploratory Factor Analysis for Scale Evaluation. Educ. Psychol. Meas. 81:001316442094289. doi: 10.1177/0013164420942899

Nguyen, T., Ansari, A., Pianta, R. C., Whittaker, J. V., Vitiello, V. E., and Ruzek, E. (2020). The classroom relational environment and children's early development in preschool. Soc. Dev. 29, 1071-1091. doi: 10.1111/sode.12447

Opdenakker, M. C. J. L. (2014). Leerkracht-leerlingrelaties vanuit een motivationeel perspectief: het belang van betrokken en ondersteunende docenten. Pedagogische Studieën 91, 332-351.

Pekaar, K. A., Bakker, A. B., van der Linden, D., and Born, M. P. (2018). Selfand other-focused emotional intelligence: development and validation of the Rotterdam Emotional Intelligence Scale (REIS). Pers. Individ. Differ. 120, 222233. doi: $10.1016 /$ j.paid.2017.08.045
Perše, T. V., Kozina, A., Vidmar, M., Veldin, M., Pivec, T., Mlekuž, A., et al. (2020). Teachers' Social, Emotional and Intercultural Competencies: predictive Value for Job Satisfaction. Sodob. Pedagog. 71, 208-225.

Peters, G.-J. Y. (2014). The alpha and the omega of scale reliability and validity. Why and how to abandon Cronbach's alpha and the route towards more comprehensive assessment of scale quality. Eur. Health Psychol. 16, 56-69. doi: $10.31234 /$ osf.io/h47fv

Pianta, R. C. (1999). Enhancing relationships between children and teachers. Washington, DC: APA, doi: 10.1037/10314-000

Pianta, R. C. (2001). Student-Teacher Relationship Scale: professional manual. Lutz, Germany: Psychological Assessment Resources.

Pillen, M., Beijaard, D., and den Brok, P. (2013). Tensions in beginning teachers' professional identity development, accompanying feelings and coping strategies. Eur. J. Teach. Educ. 36, 240-260. doi: 10.1080/02619768.2012.696192

Radloff, L. S. (1977). The CES-D Scale: a Self-Report Depression Scale for Research in the General Population. Appl. Psychol. Meas. 1, 385-401. doi: 10.1177/ 014662167700100306

Rhemtulla, M., and Hancock, G. R. (2016). Planned Missing Data Designs in Educational Psychology Research. Educ. Psychol. 51, 305-316. doi: 10.1080/ 00461520.2016 .1208094

Robinson, C. D. (2020). I Believe I Can Connect: exploring Teachers' Relational Self-Efficacy and Teacher-Student Relationships. Ph.D. thesis. Cambridge, Massachusetts: Harvard University

Roorda, D. L., Jak, S., Zee, M., Oort, F. J., and Koomen, H. M. Y. (2017). Affective Teacher-Student Relationships and Students' Engagement and Achievement: a Meta-Analytic Update and Test of the Mediating Role of Engagement. Sch. Psychol. Rev. 46, 239-261. doi: 10.17105/SPR-2017-0035.V46-3

Roorda, D. L., and Koomen, H. M. Y. (2021). Student-Teacher Relationships and Students' Externalizing and Internalizing Behaviors: a Cross-Lagged Study in Secondary Education. Child Dev. 92, 174-188. doi: 10.1111/cdev.13394

Roorda, D. L., Koomen, H. M. Y., and Oort, F. J. (2012). “An Observational Study of Teachers' Affilliation and Control Behaviours towards Kindergarten Children," in Interpersonal Relationships in Education: an Overview of Contemporary Research, eds T. Wubbels, P. den Brok, J. van Tartwijk, and J. Levy (Rotterdam: SensePublishers), 51-65. doi: 10.1007/978-94-6091-939-8_4

Roorda, D. L., Verschueren, K., Vancraeyveldt, C., Van Craeyevelt, S., and Colpin, H. (2014). Teacher-child relationships and behavioral adjustment: transactional links for preschool boys at risk. J. Sch. Psychol. 52, 495-510. doi: 10.1016/j.jsp. 2014.06.004

Roorda, D. L., Zee, M., and Koomen, H. M. Y. (2020). Don't forget student-teacher dependency! A Meta-analysis on associations with students' school adjustment and the moderating role of student and teacher characteristics. Attach. Hum. Dev. 23, 490-503. doi: 10.1080/14616734.2020.1751987

Rostad, W. L., and Whitaker, D. J. (2016). The Association Between Reflective Functioning and Parent-Child Relationship Quality. J. Child Fam. Stud. 25, 2164-2177. doi: 10.1007/s10826-016-0388-7

Roza, J. M. G., Frenzel, A. C., and Klassen, R. M. (2021). The teacher-class relationship. Z. für Pädagog. Psychol. 36, 115-132. doi: 10.1024/1010-0652/ a000328

Rucinski, C. L., Brown, J. L., and Downer, J. T. (2018). Teacher-child relationships, classroom climate, and children's social-emotional and academic development. J. Educ. Psychol. 110, 992-1004. doi: 10.1037/edu0000240

Ryan, R. M., and Deci, E. L. (2000). Self-determination theory and the facilitation of intrinsic motivation, social development, and well-being. Am. Psychol. 55, 68-78. doi: 10.1037/0003-066X.55.1.68

Sabol, T. J., and Pianta, R. C. (2012). Recent trends in research on teacher-child relationships. Attach. Hum. Dev. 14, 213-231. doi: 10.1080/14616734.2012. 672262

Schonert-Reichl, K. A., Kitil, M. J., and Hanson-Peterson, J. (2017). To reach the students, teach the teachers: a national scan of teacher preparation and social and emotional learning. A report prepared for the Collaborative for Academic, Social, and Emotional Learning (CASEL). Vancouver, B.C: University of British Columbia.

Slade, A. (2007). Reflective Parenting Programs: theory and Development. Psychoanal. Inq. 26, 640-657. doi: 10.1080/07351690701310698

Spilt, J. L., and Koomen, H. M. Y. (2009). Widening the view on teacher-child relationships: teachers' narratives concerning disruptive versus nondisruptive children. Sch. Psychol. Rev. 38, 68-101. doi: 10.1080/02796015.2009.12087851 
Spilt, J. L., Koomen, H. M. Y., and Thijs, J. T. (2011). Teacher wellbeing: the importance of teacher-student relationships. Educ. Psychol. Rev. 23, 457-477. doi: $10.1007 /$ s10648-011-9170-y

Spilt, J. L., Koomen, H. M. Y., Thijs, J. T., and van der Leij, A. (2012). Supporting teacher's relationship with disruptive children: the potential of relationshipfocused reflection. Attach. Hum. Dev. 14, 305-318. doi: 10.1080/14616734.2012. 672286

Spruce, R., and Bol, L. (2014). Teacher beliefs, knowledge, and practice of selfregulated learning. Metacogn. Learn. 10, 245-277. doi: 10.1007/s11409-0149124-0

Stacks, A. M., Wong, K., and Dykehouse, T. (2013). Teacher reflective functioning: a preliminary study of measurement and self-reported teaching behavior. Reflective Pract. 14, 487-505. doi: 10.1080/14623943.2013.806298

Thijs, J., Koomen, H., Roorda, D., and ten Hagen, J. (2011). Explaining teacherstudent interactions in early childhood: an interpersonal theoretical approach. J. Appl. Dev. Psychol. 32, 34-43. doi: 10.1016/j.appdev.2010.10.002

Tschannen-Moran, M., and Woolfolk Hoy, A. (2001). Teacher efficacy: capturing an elusive construct. Teach. Teach. Educ. 17, 783-805. doi: 10.1016/S0742051X(01)00036-1

UNESCO (2015). The challenge of teacher shortage and quality: have we succeeded in getting enough quality teachers into classrooms?. Available Online at: https://en.unesco.org/gem-report/challenge-teacher-shortageand-quality-have-we-succeeded-getting-enough-quality-teachers-classrooms (accessed August 19, 2021).

Verschueren, K. (2015). Middle Childhood Teacher-Child Relationships: insights From an Attachment Perspective and Remaining Challenges. New Dir. Child Adolesc. Dev. 2015, 77-91. doi: 10.1002/cad.20097

Verschueren, K., and Koomen, H. M. Y. (2012). Teacher-child relationships from an attachment perspective. Attach. Hum. Dev. 14, 205-211. doi: 10.1080/ 14616734.2012 .672260

Vidmar, M., and Kerman, K. (2016). The development of Teacher's Relational Competence Scale: structural Validity and Reliability. Solsko Polje 27, 41-62.

Walker, S., and Graham, L. (2019). At risk students and teacher-student relationships: student characteristics, attitudes to school and classroom climate. Int. J. Incl. Educ. 25, 896-913. doi: 10.1080/13603116.2019.1588925

Wang, H., Hall, N. C., and Taxer, J. L. (2019). Antecedents and Consequences of Teachers' Emotional Labor: a Systematic Review and Meta-analytic Investigation. Educ. Psychol. Rev. 31, 663-698. doi: 10.1007/s10648-01909475-3

Watkins, M. W. (2018). Exploratory Factor Analysis: a Guide to Best Practice. J. Black Psychol. 44, 219-246. doi: 10.1177/0095798418771807

Whitaker, R. C., Dearth-Wesley, T., and Gooze, R. A. (2015). Workplace stress and the quality of teacher-children relationships in Head Start. Early Child. Res. Q. 30, 57-69. doi: 10.1016/j.ecresq.2014.08.008

Wubbels, T., Brekelmans, M., den Brok, P., Levy, J., Mainhard, T., and van Tartwijk, J. (2012a). "Let's make things better: developments in Research on Interpersonal Relationships in Education," in Interpersonal Relationships in Education: an Overview of Contemporary Research, eds T. Wubbels, P. den Brok, J. van Tartwijk, and J. Levy (The Netherlands: Sense Publisher), 225-249.

Wubbels, T., den Brok, P., van Tartwijk, J., and Levy, J. (2012b). "Let's Make Things Better Developments in Research on Interpersonal Relationships in Education," in Interpersonal relationships in education: an overview of contemporary research, eds T. Wubbels, P. den Brok, J. van Tartwijk, and J. Levy (Rotterdam, The Netherlands: Sense Publishers).
Wubbels, T., Brekelmans, M., den Brok, P., and van Tartwijk, J. (2006). “An interpersonal perspective on Classroom Management in Secondary Classrooms in the Netherlands," in Handbook of Classroom Management: research, Practice, and Contemporary Issues, eds C. M. Evertson and C. S. Weinstein (New York, NY: Lawrence Erlbaum Associates Publishers), 1161-1191.

Wubbels, T., den Brok, P., Veldman, I., and van Tartwijk, J. (2007). Teacher interpersonal competence for Dutch secondary multicultural classrooms. Teach. Teach. 12, 407-433. doi: 10.1080/13450600600644269

Xia, Y., and Yang, Y. (2019). ). RMSEA, CFI, and TLI in structural equation modeling with ordered categorical data: the story they tell depends on the estimation methods. Behav. Res. Methods 51, 409-428. doi: 10.3758/s13428018-1055-2

Yu, S. (2018). Head Start Teachers' Attitudes and Perceived Competence Toward Inclusion. J. Early Interv. 41, 30-43. doi: 10.1177/1053815118801372

Zaretsky, R., and Katz, Y. J. (2019). The Relationship between Teachers' Perceptions of Emotional Labor and Teacher Burnout and Teachers' Educational Level. Athens J. Educ. 6, 127-144. doi: 10.30958/aje.6-2-3

Zee, M., de Jong, P. F., and Koomen, H. M. Y. (2017). From externalizing student behavior to student-specific teacher self-efficacy: the role of teacher-perceived conflict and closeness in the student-teacher relationship. Contemp. Educ. Psychol. 51, 37-50. doi: 10.1016/j.cedpsych.2017.06.009

Zee, M., and Koomen, H. M. Y. (2016). Teacher self-efficacy and its effects on classroom processes, student academic adjustment, and teacher well-being: a synthesis of 40 years of research. Rev. Educ. Res. 86, 981-1015. doi: 10.3102/ 0034654315626801

Zee, M., and Koomen, H. M. Y. (2017). Similarities and dissimilarities between teachers' and students' relationship views in upper elementary school: the role of personal teacher and student attributes. J. Sch. Psychol. 64, 43-60. doi: 10. 1016/j.jsp.2017.04.007

Zee, M., Koomen, H. M. Y., Jellesma, F. C., Geerlings, J., and de Jong, P. F. (2016). Inter- and intra-individual differences in teachers' self-efficacy: a multilevel factor exploration. J. Sch. Psychol. 55, 39-56. doi: 10.1016/j.jsp.2015.12. 003

Zijlstra, H., Wubbels, T., Brekelmans, M., and Koomen, H. M. Y. (2013). Child Perceptions of Teacher Interpersonal Behavior and Associations with Mathematics Achievement in Dutch Early Grade Classrooms. Elem. Sch. J. 113, 517-540. doi: 10.1086/669618

Conflict of Interest: The authors declare that the research was conducted in the absence of any commercial or financial relationships that could be construed as a potential conflict of interest.

Publisher's Note: All claims expressed in this article are solely those of the authors and do not necessarily represent those of their affiliated organizations, or those of the publisher, the editors and the reviewers. Any product that may be evaluated in this article, or claim that may be made by its manufacturer, is not guaranteed or endorsed by the publisher.

Copyright (C) 2022 Borremans and Spilt. This is an open-access article distributed under the terms of the Creative Commons Attribution License (CC BY). The use, distribution or reproduction in other forums is permitted, provided the original author(s) and the copyright owner(s) are credited and that the original publication in this journal is cited, in accordance with accepted academic practice. No use, distribution or reproduction is permitted which does not comply with these terms. 